Bounded Rationality as Deliberation Costs: Theory and Evidence from a Pricing Field Experiment in India

by

Dean E. Spears, Princeton University

CEPS Working Paper No. 195

October 2009 


\title{
Bounded Rationality as Deliberation Costs: Theory and Evidence from a Pricing Field Experiment in India
}

\author{
Dean Spears*
}

October 13, 2009

\begin{abstract}
How might bounded rationality shape decisions to spend? A field experiment verifies a theory of bounded rationality as deliberation costs that can explain findings from previous experiments on pricing in developing countries. The model predicts that (1) eliminating deliberation costs will increase purchasing at a higher price without impacting behavior at a lower price, (2) bounded rationality has certain greater effects on poorer people, and (3) deliberation costs can suppress screening by prices. Each prediction is confirmed by an experiment that sold soap in rural Indian villages. The experiment interacted assignment to different subsidized prices with a treatment that eliminated marginal deliberation costs. The results suggest implications of bounded rationality for theory and social policy.
\end{abstract}

*dspears@princeton.edu. Princeton University. first version: May 5th, 2009. I have many people to thank for much (though, of course, errors are my own). Priceton's Research Program in Development Studies and Center for Health and Wellbeing partially funded the fieldwork; Tolani College of Arts and Sciences in Adipur provided support. I thank Abhijit Banerjee, Roland Bénabou, Jim Berry, Anne Case, Angus Deaton, Pascaline Dupas, Thomas Eisenbach, Rachel Glennerster, Tricia Gonwa, Faruk Gul, Karla Hoff, Michael Kremer, Stephen Morris, Sam Schulhofer-Wohl, Eldar Shafir, and Marc Shotland. Vijayendra Rao provided the data on Indian marriage. P.M. Thapa assembled the survey team and spared no effort to support the project. Devjibhai got us to the participants and back. Despite this essay's use of $I$, Sarita Bangari, Beena Mishra, Mitisha Patel, Meenakshi Sharima, and Shanu Soni actually did the interviews, exceeding my hopes. The experiment could not have happened without Diane Coffey's talent and hard work. Several hundred Kucchi women have my gratitude. 


\section{Introduction}

Many economists suspect people are boundedly rational: "intentionally rational, but limitedly so" (Simon, 1957). Behavior, intuition, and the continuing attraction to modeling bounded rationality all support this view (Kreps, 1990; Conlisk, 1996; Rubinstein, 1998). I offer experimental evidence that a particular model of bounded rationality - rather than maximized standard or behavioral preferences - explains important economic behavior.

How do people, especially poor people, decide whether to spend their money? Evidence from several field experiments in development economics indicates that even for important investments in human capital, and even at very low prices, behavior is very sensitive to small changes in price (Holla and Kremer, 2009). Yet, Holla and Kremer, along with Deaton (2009) and Rodrik (2008), recognize that these findings would be most useful for policy-making with a theory that clarifies their causes and domain.

One such theory is bounded rationality as deliberation costs. In the model I present, a boundedly rational agent will only make a sufficiently expensive purchase after careful consideration, but this consideration is costly. To a sufficiently poor person, even small prices can be large enough to require deliberation. Thus, deliberation costs (1) will encourage sensitivity to small prices as found in prior field experiments, (2) will have certain larger effects on poorer agents, and (3) can prevent prices from targeting products to users with high value. The model formalizes Bertrand, Mullainathan and Shafir's (2005) intuition that bounded rationality may have different consequences for poor and rich people.

The theory is tested by a social marketing or cost sharing field experiment in Kutch, a rural district of Gujarat, India. In the experiment, some participants answered survey questions designed to require them to deliberate, leaving zero marginal deliberation costs at the time of the decision without otherwise influencing demand. Eliminating marginal deliberation costs reduces sensitivity to small prices in the way the model predicts. In addition to confirming further predictions of the theory and disconfirming alternative explanations, the experiment suggests that "economic" and "psychological" variables do not operate in isolation: prices and deliberation costs interact.

\subsection{Bounded rationality}

"Bounded rationality" is given many meanings, and sometimes merely used synonymously with "behavioral economics." By bounded rationality I mean failure to maximize expected utility over final outcomes, out of available options. Therefore I exclude both non-standard preferences - such as present bias, social preferences, anticipatory utility, motivated belief, or 
ambiguity aversion - and incomplete information, both of which are commonly incorporated into models in which agents rationally optimize in expectation.

Conlisk (1996) reviews extensive evidence that people act without optimizing over final outcomes, but also identifies obstacles to theorizing about such behavior. This essay's theory offers a tractable model of bounded rationality that makes substantive predictions for observable behavior. It combines two theoretical elements with many antecedents: choice among decision-making strategies and deliberation costs. Agents optimize only as much as is justified; it is a model of "optimal imperfection" (Baumol and Quandt, 1964).

Agents select the strategy that offers the best expected result, net of deliberation costs; therefore, they might not optimize expected utility over available final outcomes. A recent predecessor is Ergin's (2003) representation of selection of future choice sets by agents who only understand their preferences over ultimate options after costly contemplation. Like Ergin's, and as Conlisk anticipates, in technique my model resembles one of an agent optimally gathering information: "The similarity of information-gathering and deliberation, as joint inputs in producing a decision, suggests that models of deliberation, as they evolve in economics, will inevitably have a general resemblance to existing models of information collection" (690). Yet, agents acquire no new information; they process what they know to arrive at a more deliberative conclusion - or they do not.

\subsection{Pricing for the poor}

"Social marketing" programs sell products and services to poor people. Many programs adopt techniques from for-profit firms, and often products are partially subsidized. Social marketing is also known as "cost sharing": by charging, governments or NGOs share the cost of an intervention with recipients, potentially making programs more financially sustainable.

Holla and Kremer (2009) review prior field experiments with social marketing. Across several studies, they find two stylized facts:

- Small price increases, even at highly subsidized prices, have large effects: "imposing small costs consistently leads to dramatic reductions in take-up." Some studies offer "evidence the behavior is particularly sensitive to price at prices close to zero."

- Charging user fees does not "target [a product] to households that could benefit from it the most." In general, purchased products are not more likely to be used by the most vulnerable than products accepted for free.

Kremer and Miguel (2007), studying school-based deworming in Kenya, find that charging an average of thirty cents per child, rather than distributing medicine for free, reduces take-up 
by 82 percent without targeting it to infected children. Ashraf, Berry and Shapiro's (2007) experimental marketing of water disinfectant door-to-door in Zambia found large effects of price on purchasing. Yet buyers at high prices were no more likely to be pregnant or have children under five than people who accepted disinfectant for lower prices. Cohen and Dupas (2007) experimentally sold insecticide-treated bednets in Kenyan antenatal clinics. Charging sixty cents reduced take-up by 60 percent relative to free distribution; recipients who paid were no more anemic than recipients who did not.

Though not social marketing, Shampanier, Mazar and Ariely (2007) sold discounted or gave free chocolate to MIT students. They offer a choice between low and high quality chocolates for either 1 or 26 cents or 0 or 25 cents; "in the zero-price condition, dramatically more participants choose the cheaper option." They explain their findings with "affect": being free offers an emotional utility bonus. Their evidence, a separate "forced analysis" treatment arguably requiring participants to pay deliberation costs, eliminates the special effect of a zero price. In their experiments Shampanier et al. offer two prices to the same subject; this within-subject design is unable to distinguish bounded rationality from affect. By varying prices across subjects, the experiment in section 3 will be able to isolate the effect of deliberation costs.

This essay's experiment, which interacts prices with a deliberation treatment, is econometrically similar to Dupas' (2009) further investigation of pricing for bednets. Dupas interacted randomly assigned prices with "two interventions based on behavioral models designed from psychology:" being asked to make a "verbal commitment" to buying the bednet and receiving a "marketing message." Neither treatment statistically significantly interacted with prices. The experiment in section 3 differs from Dupas' study in that it specifically avoids manipulating participants' utility for the product and that it emphasizes cognitive, not social, mechanisms.

The theory in section 2 offers bounded rationality as one explanation for the findings of these experiments. Consumer behavior is complex, and these results are surely shaped by many factors. For example, Dupas (2009) finds lower price elasticity than in previous experiments; this is perhaps because participants had three months to redeem their coupons for bednets, potentially overcoming credit constraints. However, among many possible complementary explanations of these prior experiments, this essay's experiment indicates bounded rationality should be included. 


\subsection{Handwashing with soap}

Diarrheal disease kills many children in poor countries. Handwashing with soap protects against diarrheal disease. Because "the effectiveness of handwashing and point-of-use water treatment has been well established," Zwane and Kremer (2007) argue that "attention should now be given to efforts to understand effective promotion strategies and how to sustain behavior change" (7). How can people be encouraged to acquire and use soap?

One popular answer is selling soap specifically to the poor. ${ }^{1}$ Easterly (2006) recounts the tale of Lifebuoy Swasthya Chetna, the social marketing program that resulted when Hindustan Lever Limited "realized [they] could find a larger market if they were tied to preventing diarrheal diseases for the poor" (12). As Neath (2006), Unilever's Senior Vice President for Global Corporate Responsibility, observes, "getting people to understand the need for handwashing is one thing, persuading them to buy a bar of soap is another." Unlike the social marketing programs surveyed by Holla and Kremer, Swasthya Chetna did not subsidize soap. "To help people on low incomes a small 18gm bar of Lifebuoy has been introduced... this sells for the equivalent of 2 rupees." At 0.111 rupees per gram, this soap cost more than the regular bars of Lifebuoy soap I found in Kucchi villages (table 4).

In this essay's field experiment in Kutch, surveyors sold packages of Lifebuoy soap doorto-door at two experimentally varied, discounted prices. Random assignment to either a low or a very low price of soap was interacted with assignment to a control group or a treatment group in which marginal deliberation costs are eliminated. What appeared to be survey questions actually required treatment group participants to contemplate the offer. The theory predicts, and the model finds, that the treatment promotes buying only at the higher price. This effect is greater for poorer participants, and only without deliberation costs does a higher price concentrate adoption on participants with greater need.

\section{Theory}

I model bounded rationality as deliberation costs. A boundedly rational agent is unsure whether an offer is worth accepting; despite full information, she cannot automatically recognize which behavior is optimal. She can compute with certainty whether or not accepting the offer would maximize her expected utility by paying a utility cost of thinking. If she does not consider the offer carefully she does not pay the deliberation cost, but runs the

\footnotetext{
${ }^{1}$ Advocates of social marketing contend that charging makes programs "sustainable." Yet, Kremer and Miguel (2007) explain that sustainability may be a misplaced ideal: the social value of human capital investments with positive externalities may substantially exceed private willingness to pay. Soap, which diminishes disease transmission, has such externalities (Luby et al., 2004).
} 
risk of making a wasteful purchase. When made an offer, she chooses among deliberating, accepting without deliberation, and rejecting without deliberation. ${ }^{2}$

This model is stylized. It isolates one agent and one decision, ignoring markets and time. While generalizing decision-making to include selecting a strategy to decide, it ignores higher-level strategies (how to decide how to decide...) that may infinitely regress. These abstractions permit a tractable model with verifiable predictions.

\section{$2.1 \quad$ Model}

An agent must decide whether to accept an offer to buy a good at a price. If she accepts, she pays a price $p$ and receives utility $\tilde{x}$. She decides by comparing the expected utility of the good with the opportunity cost of spending $p$, which depends on her wealth $w$ and her concave, increasing utility for wealth $u(\cdot)$. Is $\mathrm{E}[\tilde{x}]>u(w)-u(w-p)$ ?

However, she is boundedly rational: she only understands the utility consequences of accepting an offer after costly deliberation. I consider two formal frameworks for bounded rationality with almost identical behavioral consequences and with identical implications for the experiment. In one interpretation the agent knows the utility from the offer, $\tilde{x}$, only after deliberating; for example, a villager considering soap could remember her children's recent diarrhea, assess whether members of her family would use the soap, and compute how long an unusually large package would last relative to other offers at other prices. In the other interpretation the agent knows the marginal disutility of spending $p$ only after deliberating; thus she might consider future demands on her money, who in her household will spend the money if she does does not, and the cost of otherwise fulfilling the same needs.

In either case, the agent observes initial signals $x$ and $u(\cdot)$, first impressions about the quality of the offer or her utility for wealth which may not be trustworthy. Only by paying an additive utility cost of deliberation, $c>0$, can the agent figure out the true values.

If bounded rationality is interpreted to be about the good, $\tilde{x}$, her uncertainty is simple: with probability $\pi \in[0,1]$ the offer is as good as it seems and $\tilde{x}=x$, but with probability $1-\pi$ the good is worthless to her and $\tilde{x}=0 ; u(\cdot)$ is correct. If she is boundedly rational about the marginal utility of money then $x=\tilde{x}$, but only with probability $\pi$ is $u(\cdot)$ her utility for wealth; with probability $1-\pi$ it is $\lambda u(\cdot)$, where $\lambda$ is a multiplier greater than one. In either interpretation, she has three options: buy without deliberating, reject the offer without deliberating, or think and then buy only if her signal is correct. Ex ante, these

\footnotetext{
${ }^{2}$ This is an example of what Conlisk (1996) calls an " $F(P)$ problem." $P$ is the problem of selecting a behavior; $F(P)$ asks how to solve it given deliberation costs. Thus, if $X$ is a behavior, $\Pi(\cdot)$ maps behaviors to profits, $T$ is a quantity of thinking, and $C$ is a per-unit deliberation cost, $P$ requires agents to "choose $X$ to make $\Pi(X)$ large," while $F(P)$ asks they "choose $T$ to make $E\{\Pi[X(T)]\}-C T$ large" (689).
} 
Table 1: Three strategies, two interpretations

\begin{tabular}{lll}
\hline \hline bounded rationality concerns: & the offer $x$ & utility for wealth $u(\cdot)$ \\
\hline buy without deliberating & $\pi x+u(w-p)$ & $x+[\pi+(1-\pi) \lambda] u(w-p)$ \\
deliberate before buying & $\pi[x+u(w-p)]$ & $\pi[x+u(w-p)]$ \\
& $+(1-\pi) u(w)-c$ & $+(1-\pi) \lambda u(w)-c$ \\
& $u(w)$ & {$[\pi+(1-\pi) \lambda] u(w)$} \\
reject without deliberating & & \\
\hline
\end{tabular}

three options offer the expected utilities in table 1.

Which strategy will the agent pursue? If the agent were perfectly rational, with $c=0$, she would deliberate about each good that she might buy. She would consider every offer with $x>v(p, w)$, where $v(p, w)=u(w)-u(w-p)$, the opportunity cost of spending $p$ at wealth $w$. Because of the concavity of $u$,

$$
v_{p}>0, v_{w}<0, \text { and } v_{p w}<0 .^{3}
$$

This defines a threshold: a perfectly rational agent deliberates if $x>\bar{x}(p, w) \equiv v(p, w)$ and buys if she finds accepting offers positive net utility.

However, the agent is not perfectly rational, and must decide whether to think. She prefers buying without thinking to rejecting the offer without thinking if and only if

$$
x>\bar{x}^{N T}(p, w) \equiv \gamma v(p, w) .
$$

The multiplier $\gamma>1$ establishes distance between $\bar{x}^{N T}$ and $\bar{x}$ that is increasing in $p \cdot{ }^{4}$ Both thresholds are zero when price is - any good with the possibility of value is worth accepting for free - but the minimum value required to buy unthinkingly increases in price more quickly than does the minimum value for a perfectly rational agent. This conservatism is an implication of Spence and Zeckhauser's (1972) demonstration that "requiring an individual to make consumption decisions... before a lottery is resolved will make him substantially more eager to face a lottery which... offers little variance" (402).

For thinking to be optimal, the benefits of thinking must outweigh the deliberation costs. If the agent deliberates she will only pay $p$ if the good is valuable, but she pays $c$ whether

\footnotetext{
${ }^{3}$ Additionally, $v_{p p}>0$, but, because $x$ and $u$ are together unique only up to a positive transformation, this has no revealed preference implications.

${ }^{4}$ When bounded rationality concerns $x, \gamma=\frac{1}{\pi}$; when it concerns the utility of wealth, $\gamma=\pi+(1-\pi) \lambda$.
} 
or not she decides to buy. She prefers thinking to preemptive rejection if and only if

$$
x>\bar{x}^{T}(p, w) \equiv v(p, w)+\frac{c}{\pi}
$$

The signal $x$ must exceed the value of the price by enough to compensate for deliberating: it would not be worth thinking to buy a good only slightly better than its price. The minimum signal $\bar{x}^{T}$ is increasing in price at the same rate as $\bar{x}$ but additionally requires $\frac{c}{\pi}$ at the origin.

Whether costly deliberation is preferable to simply buying the good depends on the utility at stake in the risk of wasting money and on the costs of thinking. Deliberation is preferred to thoughtless buying, whether or not either is preferred to rejecting the offer, only if ${ }^{5}$

$$
v(p, w)>\frac{c}{\pi(\gamma-1)}
$$

Let $\bar{x}^{B R}(p, w)$ indicate the minimum signal $x$ above which a boundedly rational agent will either purchase or consider purchasing the good at price $p$; below this cutoff, a boundedly rational agent does not buy the good.

Proposition 1. There is a price cutoff $p^{*}(c, w, \pi, \gamma)$, below which the agent will only buy the good if its signal merits buying without deliberation, and only above which will she deliberate about the offer. This price point is independent of the good or signal, $x$.

$$
\bar{x}^{B R}(p, w)=\left\{\begin{array}{ll}
\bar{x}^{N T}(p, w) & p \leq p^{*} \\
\bar{x}^{T}(p, w) & p>p^{*}
\end{array} .\right.
$$

The existence of $p^{*}$ follows directly from condition 3 . The shape of $\bar{x}^{B R}$ results from the combination of conditions 1,2 , and 3 .

Figure 1 depicts the agent's buying behavior. The threshold that determines behavior, $\bar{x}^{B R}$, is indicated by the heavy line. The shaded area between $\bar{x}$ and $\bar{x}^{B R}$ is the set of potentially profitable offers forgone due to deliberation costs. These are offers that an unboundedly rational agent would consider and that may offer more utility than the opportunity cost of their price, but that the boundedly rational agent will not consider or accept.

The sensitivity to small prices highlighted by Holla and Kremer's review of pricing field experiments may be due to the ignored offers between $\bar{x}$ and $\bar{x}^{B R}$ : free goods are not affected by deliberation costs but offers for sale are. Especially at the low prices these experiments

\footnotetext{
${ }^{5}$ When bounded rationality concerns $x$, deliberation is preferred if and only if condition 3 holds. When bounded rationality concerns $u(\cdot)$, deliberation is preferred to buying outright if and only if 3 holds and $x<\lambda v(p, w)-\frac{c}{1-\pi}$; if the good is sufficiently valuable sparing deliberation costs could be worth the risk. This third threshold also intersects $\bar{x}^{N T}$ and $\bar{x}^{T}$ at $p^{*}$.
} 
emphasize, the boundedly and unboundedly rational thresholds are diverging steeply; above $p^{*}$ they remain separated by $\frac{c}{\pi}$.

\subsection{Comparative statics}

\subsubsection{Eliminating deliberation costs}

The field experiment in section 3 requires some participants to deliberate about a purchase, reducing marginal deliberation costs at the time of the decision to zero. What effects does this model predict of a change from $c>0$ to $c=0$ ?

If $c=0$ then condition 3 is satisfied whenever $p>0$ and $\pi<1$ : thinking is preferred to simply buying whenever money is at stake, as long as there is some possibility of the offer not being valuable. Because $\frac{c}{\pi}=0, \bar{x}^{B R}$ collapses to $\bar{x}$ and the agent considers each offer that, if valuable, would be worth more than the opportunity cost of its price.

As figure 2 depicts, this has a first order and a second order effect. The first order effect is to cause all potentially profitable offers to be considered, eliminating the shaded area. Therefore, in the figure, the good would be considered at the higher price $p^{h}$ only after deliberation costs have been reduced. If $x>\bar{x}^{B R}(p, w)$ there is no first order effect; depending on the distribution of $x$, meeting this threshold may be more likely at low prices, where the set of foregone offers occupies a shorter range of signals.

The second order effect impacts some offers that are accepted with deliberation costs. Accepted offers with $p>p^{*}$ were carefully considered and bought because, to illustrate with the case of bounded rationality about the good, $\tilde{x}=x$. Accepted offers with $p<p^{*}$ will only now be deliberated about, however, and a fraction $1-\pi$ will no longer be purchased when $\tilde{x}$ is revealed to be zero. Therefore, at $p^{\ell}$ there would be no first order effect of eliminating $c$, but the probability of acceptance will fall by $1-\pi$.

Proposition 2. Changing $c>0$ to $c^{\prime}=0$ eliminates the set of profitable offers foregone due to bounded rationality.

- There is no first order effect inducing purchasing if the agent would buy the good at $c>0$.

- The width of the range of signals $x$ in which changing c to 0 induces purchasing is weakly increasing in $p$, and strictly increasing when $p$ is small.

- If the agent would buy the good at $c>0$ and only if $p<p^{*}$ then changing $c$ to 0 has a second order effect of reducing the probability of acceptance by $1-\pi$. 


\subsubsection{Wealth}

How do richer agents, with higher $w$, compare to poorer agents? Figure 3 presents a representative illustration. Richer agents can afford to think less about consumption. Their opportunity cost of money $v(p, w)$ is lower and increasing less quickly.

Proposition 3. For any $u, \pi$, and $c$ :

- $\frac{\partial p^{*}}{\partial w}>0$ : Deliberation is required to make a purchase at lower prices for poorer agents than for richer agents.

- $\frac{\partial \mathcal{L}}{\partial w}<0$ : The area of the set of potentially profitable offers ignored is smaller for richer agents.

A proof is presented in appendix section A.1.

Thus, if a richer agent who accepts an offer deliberates, a poorer agent who accepts the same offer also deliberates. The ultimate consequences for buying behavior depend on the equilibrium distribution of offers $(x, p)$ to poor and rich agents: in practice poor and rich people buy and are offered different goods. A rich person with a high $p^{*}$ may pay more deliberation costs than a poor person with a low $p^{*}$ if, for example, the rich person receives more offers, or if the offers are sufficiently expensive that the poor agent would not buy them even without deliberation costs. Offers made by social marketing programs are made to the poor and carry low prices; proposition 3 suggests that in precisely these situations deliberation costs will tax the poor most.

\subsubsection{Skepticism and deliberation costs}

How does behavior change after continuous changes in $c$ and $\pi$ ? "Behavioral" outcomes are often taken to be negligible when their causes are "small." This section formalizes that this intuition holds in the case of deliberation costs.

Proposition 4. As deliberation costs and uncertainty become small, buying behavior converges to the unboundedly rational case.

- $\frac{\partial p^{*}}{\partial c}>0$ : Higher deliberation costs encourage buying without thinking.

- $\frac{\partial p^{*}}{\partial \pi}>0$, when bounded rationality concerns $x$ : Greater certainty encourages buying without thinking.

- As $c \rightarrow 0, \bar{x}^{B R}(p, w)$ converges uniformly to $\bar{x}(p, w)$ for all $w$. 
- As $\pi \rightarrow 1, \bar{x}^{B R}(p, w)$ converges pointwise to $\bar{x}(p, w)$ for all $w$.

A proof is presented in appendix section A.2.

These asymptotically similar results have different intermediate implications for deliberation. To illustrate with the case where bounded rationality concerns $x$, as $c$ goes to zero, the agent approaches always deliberating; therefore she always pays (ever smaller) deliberation costs and does not buy the fraction $1-\pi$ of goods that are worthless. As $\pi$ goes to one, the agent approaches never deliberating; she never pays the unchanging, positive deliberation costs but does buy some goods - in ever smaller frequency — that are worthless. In the limit in both cases the agent pays no deliberation costs (because there are not any, or because she does not pay them) and purchases no worthless products (because she identifies them all, or because there are not any).

\subsection{Deliberation costs and screening}

Holla and Kremer observe that "advocates of charging [for education and health services and products]... note that charging may screen out those who place low value on the product or service, thus concentrating take-up on those who value it most." If so, charging could make distribution programs more effective: a higher fraction of resources are used where they would be most valuable.

However, the experiments Holla and Kremer summarize find no evidence of higher prices "targeting" products to those who would value them more. While this could occur among perfectly rational consumers, especially if those with the highest value for the good are also the poorest, deliberation costs can generate or exacerbate a failure of prices to target even if the distribution of $x$ is independent of wealth. No theorem is available - any particular outcome depends on the distribution of $x$-but plausibly general implications of this model for cross-sections of agents suggest that higher prices will often better target adoption to those with higher value when there are no deliberation costs.

Deliberation costs raise $\bar{x}^{B R}$ above $\bar{x}$, requiring higher perceived value $x$ at every price. Proposition 3 demonstrated that this increased requirement, and its sacrifice of potentially profitable offers, is greater for poorer agents. Yet, it is exactly the poor for whom the difference between two prices - particularly the small prices studied in the social marketing field experiments - would be most relevant and most likely to screen out agents with higher values.

Deliberation costs are most likely to prevent poorer agents from considering or accepting an offer. Yet, poorer agents are most likely to be sensitive to price, such that price separates values $x$. Therefore, deliberation costs can suppress a screening effect of higher prices. 
Table 2: Deliberation costs and screening

\begin{tabular}{cccccccc}
\hline \hline & & & poor & middle & rich & count & $x^{h} \%$ \\
\hline$c>0$ & $p^{h}$ & $x^{h}$ & & & $\checkmark$ & 1 & \\
& & $x^{l}$ & & & $\checkmark$ & 1 & \\
& & & & & 2 & $50 \%$ \\
\cline { 2 - 7 } & $p^{l}$ & $x^{h}$ & & $\checkmark$ & $\checkmark$ & 2 & \\
& & $x^{l}$ & & $\checkmark$ & $\checkmark$ & 2 & \\
& & & & & & 4 & $50 \%$ \\
\hline \multirow{2}{c}{$=0$} & $p^{h}$ & $x^{h}$ & $\checkmark$ & $\checkmark$ & $\checkmark$ & 3 & \\
& & $x^{l}$ & & $\checkmark$ & $\checkmark$ & 2 & \\
& & & & & & 5 & $60 \%$ \\
\cline { 2 - 7 } & $p^{l}$ & $x^{h}$ & $\checkmark$ & $\checkmark$ & $\checkmark$ & 3 & \\
& & $x^{l}$ & $\checkmark$ & $\checkmark$ & $\checkmark$ & 3 & \\
& & & & & 6 & $50 \%$ \\
\hline
\end{tabular}

Table 2 illustrates this possibility with an example designed to explain the results of the field experiment in section 3. Wealth $w$ and value $x$ are jointly uniformly distributed. Agents are either poor, middle, or rich, with $w_{p}<w_{m}<w_{r}$ and have either high or low private value for a good, $x_{\ell}<x_{h}$. To emphasize: poor and rich agents experience the same cognitive costs and have the same distribution of value. The table summarizes who buys when the six agents are offered the good in each of four situations: at a high or low price, $p_{\ell}<p_{h}$, and with or without deliberation costs, $c>0$ and $c=0$.

Rich agents have sufficiently low $v(p, w)$ that, with $x_{\ell}$ or $x_{h}$, they buy the product at either price, even under deliberation costs. All middle agents are like those depicted in figure 2: with deliberation costs they buy the good at $p_{\ell}$ but at $p_{h}$ they reject the offer, which falls into their region of missed profitable offers. Without deliberation costs there is no such region and they buy the product at either price, even with the lower value for the good.

Poorer agents are as in figure 4. Without deliberation costs, the higher price would screen out agents with value $x_{\ell}$ while retaining agents with value $x_{h}$. With deliberation costs, neither type considers nor buys the good.

The outcomes where $c>0$ correspond to the experiments summarized by Holla and Kremer. There is a large effect of the increase in price on the number of people buying the good, but no effect on the proportion of those who buy who have $x_{h}$. Where $c=0$, the effect of price on acceptance of the offer is smaller and an increase in price increases the fraction of buyers having higher value for the good. 


\section{$3 \quad$ Field experiment}

The theory in section 2 argued that bounded rationality can cause small prices to have large effects on offer acceptance and will cause potentially profitable offers to be ignored, especially among the poor. Moreover, deliberation costs can prevent prices from sorting recipients by their value for the product.

An experiment in rural villages in Kutch, India tested these predictions with door-todoor sales of hand and body soap at two randomly assigned prices. The findings of the prior pricing experiments surveyed by Holla and Kremer all occurred in the context of whatever positive deliberation costs were independently present. The experiment in Kutch replicates these findings in a control group with deliberation costs. To test whether bounded rationality explains these results, in a treatment group marginal deliberation costs at the time of the decision were manipulated to be zero. Thus, assignment to high or low prices was experimentally crossed with deliberation treatments to create four experimental groups. Each participant was randomly assigned to one group. The results matched the theory.

\subsection{Procedure}

\subsubsection{Context}

In March and April 2009, surveyors visited 13 rural villages $^{6}$ in Kutch, the largest district in Gujarat, India. Kutch is an arid region substantially covered by salty desert and bordering Pakistan. The villages were concentrated in the Anjar and Gandhidham blocks. According to a 2001 government map, all villages in the study had a population below 2,000 and most between 500 and 1,000. ${ }^{7}$ The experiment was conducted in Gujarati.

March and April are in the "hot season" of Gujarat. People believe that children are especially susceptible to diarrhea during these months. Thirteen percent of women in my sample with children in their household report at least one child having had a loose stool in the previous week. This implies statistically significantly more than the global median rate of 3.2 episodes of diarrhea per child-year found by Kosek et al. (2003). ${ }^{8}$

Surveyors made unannounced visits to participants' houses to conduct the experiment. They were instructed to visit every house admissible under the experimental protocol. ${ }^{9}$ The

\footnotetext{
${ }^{6}$ Ambapar, Devaliya, Gopalnagar, Hatdi, Lakhapar, Mitha Pasvariya, Mithi Rohar, Nagavadalia, Satapur, Tapar, Varasamedi, Veera, and Vidi.

${ }^{7}$ This is the most recent and only available map; much has changed in Kutch since a 2001 earthquake.

${ }^{8}$ It is 13 percent of women who report diarrhea, and many women have multiple children; to be conservative, if each has only one child with a loose stool, 11.6 percent of children do. $\frac{3.2 \text { episodes per year }}{52 \text { weeks per year }}=0.0616$ episodes per week. With $\bar{x}=0.116$ and $\mu_{0}=0.0616, t=4.33$.

${ }^{9} \mathrm{~A}$ house might be inadmissible if a woman declined to participate, if the surveyor could not conduct the
} 
experiment was conducted only with adult women; surveyors were trained not to interview a woman if anybody other than small children were present. ${ }^{10}$ In addition to ethically promoting anonymity, privacy ensured that the experiment was focused on individual decisionmaking, not social preferences or signalling. A research assistant who understood English, Hindi, and Gujarati made spot checks on the surveyors to enforce the protocol.

\subsubsection{Product and prices}

Participants were offered a package of two 120 gram bars of Lifebuoy brand soap. Lifebuoy is one of two brands of soap in Kutch marketed for health rather than beauty; it claims to provide "long lasting protection from germs." The other pro-health brand, Dettol, is substantially more expensive by weight. A social marketing program by Hindustan Lever Limited that sold Lifebuoy in rural Indian villages is cited enthusiastically by Easterly (2006).

Participants would have been familiar with the soap. In almost every village I found at least three brands of soap for sale, and in most about five; Lifebuoy was regularly among them. Yet, many participants do not generally purchase or use body soap, so its offer may require deliberation. That the soap was pre-packaged into bundles of two bars clarified to participants that they were being offered the set.

Soap was offered at the "low" price of 3 rupees and the "high" price of 15 rupees. Like in previous social marketing experiments, these represent subsidies of 88 and 42 percent of the market price and 87 and 33 percent subsidies of the lowest price of soap found in any village. Even at 15 rupees, as table 4 shows, the soap was less expensive by weight than any other soap found for sale in these villages. The table omits sachets, small packets of liquid or powdered soap, shampoo, or detergent that people often buy because of their low prices, despite very low volume; a sachet of shampoo from an experimental village cost three rupees for eight milliliters.

Some soaps' packages report a "toilet soap grade" of 1, 2, or 3. A 0.1 rupees-per-gram increase in the price of the soap in my sample is associated with a 30 percentage point increase in the linear probability of being grade 2 or 3 rather than grade 1 (s.e. $=0.148$ ). Lifebuoy is grade 3 .

interview alone with the participant, or if the surveyor believed the participant had already witnessed or heard about the experiment.

${ }^{10} \mathrm{In}$ one case, a random check revealed a surveyor to be interviewing a woman with other adults present. The surveyor explained that the other adults spoke only Kucchi and would not have understood the experiment in Gujarati. Because this nevertheless may have changed the individual decision-making nature of the experiment, all interviews by this surveyor were discarded in that cluster. 


\subsubsection{Thinking treatment}

To determine the effects of deliberation costs, I experimentally manipulated them. Participants assigned to a treatment group were indirectly required to deliberate about whether they should buy the soap immediately before actually being required to choose. Because they had already deliberated, at the time of their decision marginal deliberation costs were smaller than without the treatment, and possibly zero.

Specifically, participants in the treatment group were asked a series of questions that appeared to be ordinary survey questions. Surveyors wrote down responses as if learning the answers were the goal. However, these questions were in fact designed to lead participants through deliberation about the offer. Participants in the control group were asked a matched set of irrelevant questions. Both sets of questions are reported in appendix section B.

Care was taken to equalize the duration and cognitive and emotional intensity of thinking and control questions; balanced questions could avoid spurious effects of mental depletion, confusion, or experimenter demand. Additionally, control questions were written to avoid a direct effect on the soap decision, such as by invoking wealth or social status. Each control question was matched to a thinking question in grammar, form of response (numerical, comparative, or open-ended), and expected fatigue. While in English there are 123 words in the thinking questions and 116 in the control questions, in Gujarati there are 126 and 125 words, respectively. A research assistant present for many interviews reports that among a surveyor's interviews, treatment and control questions took approximately the same time.

Care was also taken to avoid prejudicing the results of deliberation. For example, a question was asked that highlighted the opportunity cost of spending $p$ ("How much flour could you buy for $p$ rupees?" presumably a positive amount) and another was asked demonstrating an upper bound on this opportunity cost ("Could you buy a bucket for $p$ rupees?"; participants could almost certainly not). Additionally participants were asked to give a reason buying the soap would be a good idea and a reason it would not. The order of the good and

bad reasons was randomly counterbalanced to avoid question order effects, as was the order of good and bad aspects of participants' native villages in the control group.

To increase the probability that deliberation happened only according to the experimental protocol, surveyors were instructed not to interview women who appeared to have already heard about the experiment from neighbors. We visited each village only once, and conducted interviews for no more than a few hours.

The thinking treatment is similar to "debiasing" experiments in cognitive psychology. Fischhoff (1982) describes debiasing as "destructive testing" of decision-making anomalies, often seeking "to discover the boundary conditions for observing biases." A common debias- 
ing technique used in this experiment's thinking treatment is to ask participants to generate reasons, in this case to buy the soap and not to buy the soap. Schwarz et al. (2007) warn about the "metacognitive" effects of this debiasing strategy, the effects of the experience of thinking. Their experiments show that when people have difficulty producing arguments for a proposition, they tend to believe there are few. Asking a participant to list many benefits of an activity may make her less likely to select it than asking her to list fewer; the increased difficulty she has finding the marginal benefits persuades her that they are scarce. This is particularly relevant to the experiment in Kucchi villages: almost half of the participants never attended school, and even those who did found the experiment unusual. To avoid this complication, the treatment asks for only one reason of each type.

Social psychologists have found that people are more likely to ultimately undertake actions to which they are asked to verbally commit. Making a commitment appears to change people's preferences by inducing them to signal to themselves that their preferences are different (Bem, 1967). To isolate cognitive mechanisms, the thinking treatment does not ask participants whether they will or should buy the soap.

\subsubsection{Econometric strategy}

According to proposition 2 from section 2.2.1, eliminating deliberation costs should increase take-up at a high price that falls within the range of foregone profitable offers, but should have no effect, or a slightly negative effect, on take-up at a low price. To test this proposition, I make two ancillary assumptions: that 15 and 3 rupees constitute such high and low prices, and that the thinking questions eliminated marginal deliberation costs at the time of the decision, but had no other effect relative to the control questions.

With two experimentally crossed treatments, I can estimate the saturated model

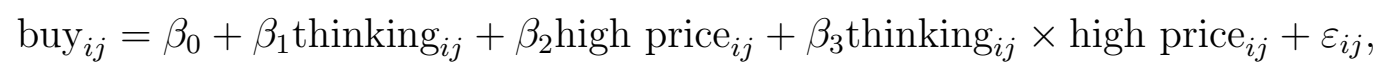

where $b u y_{i j}$ is a binary indicator of whether the participant bought the soap, thinking $g_{i j}$ is a dummy variable indicating having been assigned to the thinking treatment, and high price ${ }_{i j}$ is a dummy for a 15 rupee price. Index $i$ identifies participants; $j$ represents the clustering of the data.

The theory predicts:

- $\beta_{1}=0$. Thinking has no effect, or a slightly negative effect, at three rupees.

- $\beta_{2}<0$. Charging the higher price reduces take-up in the control group. 
- $\beta_{3}>0$. Encouraging thinking reduces the effect of the change in price by increasing take-up at the high price.

\subsection{Validity}

\subsubsection{Randomization balanced observable characteristics}

Table 5 presents summary statistics of answers to survey questions. These few survey questions, asked in order to assess balance of experimental groups, followed the experimental treatments and soap decision, and may have been influenced by them. Survey questions must either precede or follow the experimental decision whether to buy soap; whichever came second could be tainted. Rather than counterbalance their order, I chose to focus on the validity of the experiment.

The results are unsurprising in this population. The average household has five members, and in 85 percent at least one of these is a child. Approximately half of the participants ever attended school and almost twenty percent live in their native village.

Fifty-five percent of participants reported in a question at the end of the interview that they bought soap "the last time that [they] went to the market." This high figure almost certainly includes some experimenter demand: the question came after an experiment that demonstrated the surveyor cares about soap and may have been a way to politely excuse not having bought soap from the surveyor. Additionally, while surveyors were trained to specify body and hand soap, many participants may not have distinguished laundry detergent or sachets of shampoo, which could be bought frequently in very small quantities. Participants were not asked to show soap to surveyors but a research assistant reports that many participants did not appear to possess soap.

My causal interpretation of the coefficients in regression equation 5 is grounded in the random assignment of treatment and control groups, stratified by cluster and surveyor. The experiment used eight different scripts: $\{3$ rupees, 15 rupees $\} \times\{$ treatment, control $\} \times$ \{good reason first, bad reason first\}. ${ }^{11}$ Each surveyor received experimental forms in paperclipped packets of eight in opaque envelopes. These forms were in a random order independent across packets, ${ }^{12}$ and numbered in green pen (so it could not be changed). Only after participants had agreed to participate after hearing an oral consent script, and after the surveyor was alone with a participant, was the participant assigned a script by the sur-

\footnotetext{
${ }^{11}$ As described in section 3.1.3, the order of the request for positive and negative reasons was randomized simply to counterbalance any effect of asking either first; it was not an experimental treatment and had no hypothesized effect.

${ }^{12}$ Usually, I used a table of random digits; on one occasion I used a die to demonstrate the concept to the surveyors, and once or twice in a pinch in the field I shuffled papers and blindly pulled them out of a bag.
} 
veyor's removal of the next form from the envelope. Assignment was clearly not double-blind (surveyors knew which form they were reading), but surveyors did not know my hypotheses. After completing a set of eight forms, surveyors returned to the jeep for a new packet from me. Surveyors were trained not to look in the envelope at upcoming forms. A research assistant and I intercepted surveyors throughout the day to verify their compliance with randomization protocols.

Randomization achieved sufficient balance across experimental groups that no observed characteristics statistically significantly differ. Table 5 presents means and standard errors for each group, as well as the $F$ statistic testing the fit of a saturated model.

Although the independent variables in regression equation 5 use initial assignment, attrition and compliance are not problems in this experiment. Participants had a single, approximately ten-minute interaction with surveyors. Once participants agreed to the experiment and were randomly assigned a treatment group, they were counted as having not bought the soap if the interview stopped, or under any outcome other than buying the soap. This only happened in 3.4 percent of cases; the last row of table 5 confirms that stoppage is not differentially likely in experimental groups. Column 3 of table 6 will report that results are robust to omitting these 22 participants.

\subsubsection{The thinking treatment encouraged thinking}

While the answers to the thinking questions were never intended to be part of the experimentasking them was the point - the surveyors were instructed to report them. The answers were not nonsense. For example, while only 5 percent of participants offered soap for three rupees thought they could find the same quantity at a lower price, 19 percent of those offered it for fifteen rupees thought so.

Answers to thinking treatment questions proved to be associated with buying behavior. Among the 324 participants asked, participants who believe the soap will last ten days are 5.6 percentage points more likely to buy (s.e. $=0.053$ ), those who believe they can get a lower price are 22.4 percentage points less likely to buy (s.e. $=0.080$ ), and those who believe they will need the rupees in the next ten days are 9.8 percentage points less likely to buy (s.e. $=0.055)$. These suggest that participants were indeed considering the thinking questions in deciding whether to buy. 
Table 3: Price elasticities of demand: four experiments

(4)

(5)

\begin{tabular}{ccccc}
$\begin{array}{c}\text { deworming } \\
\text { Kenya }\end{array}$ & $\begin{array}{c}\text { bednets } \\
\text { Kenya }\end{array}$ & $\begin{array}{c}\text { disinfectant } \\
\text { Zambia }\end{array}$ & $\begin{array}{c}\text { control } \\
\text { Kutch }\end{array}$ & $\begin{array}{c}\text { treatment } \\
\text { Kutch }\end{array}$ \\
\hline-0.69 & -0.68 & -0.6 & -0.71 & -0.54
\end{tabular}

\subsection{Results}

\subsubsection{Deliberation costs: Proposition 2}

Figure 5 reveals the main result of the experiment. In the control group 84.0 percent bought soap when offered for three rupees and 29.8 percent bought soap sold for fifteen rupees. Among those asked to deliberate, 82.4 percent bought soap for three rupees and 39.0 percent bought soap for fifteen.

Column 1 of table 6 presents this intention-to-treat result as a linear probability regression: proposition 2 is matched. The thinking treatment had almost no direct effect among those offered soap for three rupees; it was associated with a statistically insignificant decline in purchasing of 1.5 percentage points. ${ }^{13}$ In the control group, like in the experiments surveyed by Holla and Kremer, the higher price caused a 54.1 percentage point decrease in take-up. The experimental assignments interacted: while the thinking treatment had little effect at three rupees, it increased acceptance by 10.7 percentage points - or 36 percent - at fifteen rupees.

Table 3 compares these effects with those from previous experiments. Its computation is detailed in appendix section A.3. Despite being dependent on the particular prices, places, and methods of each trial, price elasticities of demand found in Kremer and Miguel's deworming, Cohen and Dupas' bednets, and Ashraf et al.'s water disinfectant experiments are strikingly similar to the elasticity in the Kucchi control group. The treatment group displayed less price elasticity than found in any of these studies.

Like in Shampanier et al.'s chocolates experiment's "forced analysis" condition, the thinking treatment diminished the effect of a change in price. ${ }^{14}$ However, the thinking treatment

\footnotetext{
${ }^{13}$ This small decline could be sampling error, or it could reflect the fraction $1-\pi$ concluding the soap would not be valuable to them. Whatever its cause, the negative sign of the thinking treatment at three rupees makes some alternative explanations of the experiment's results unlikely. For example, the thinking treatment might suggest that the participant's "guest" wants her to buy the soap; this "experimenter demand" would be more probably effective at the three rupee price of a cup of tea that might be served. Potentially twenty percent of the population would never buy soap under any circumstances; however the possibility that the results are driven by a fixed, soap-disliking group appears unlikely in light of pilot results at lower prices where more participants bought soap and the fact that the pattern of results remains when the sample is split.

${ }^{14}$ The experiments are not directly comparable: unlike in their chocolates experiment, no soap was free.
} 
did not diminish any affect attached to the low price; it had no statistical effect at three rupees. Instead it increased acceptance at the high price. Because participants offered the soap for fifteen rupees had no exposure to the low price, the thinking treatment could not have worked by encouraging cognition to outweigh positive emotion about the low price's bargain, Shampanier et al.'s explanation of their results.

Standard price theory, special emotion about low prices, and "behavioral" preferences such as present bias all fail to predict $\beta_{3}>0$. Theories of social preferences predict $\beta_{1}>0$ (people would be more likely to buy merely to please the experimenter when doing so is less expensive), yet $\hat{\beta}_{1}$ is statistically zero and slightly negative. Bounded rationality as deliberation costs correctly predicts all three coefficients.

Two econometric issues remain. Is the estimate of $\beta_{3}$, the coefficient on the interaction, robust to plausible respecifications? With clustered standard errors known to produce tests of larger than theorized size in finite samples, is the inference that $\beta_{3}>0$ credible?

Column 2 of table 6 omits the last interview in each packet of eight. In principle, a surveyor could have memorized the first seven interviews and known with certainty which price and treatment assignment would be next. While I have no evidence of this happening, this could have permitted a departure from the protocol of randomly assigning the experimental group only after receiving informed consent. When these interviews are omitted the coefficients are similar, indeed greater in magnitude.

Interviews that were stopped or ended in any way other than a sale of soap are counted as the participant not having bought soap. This is both for external validity — whether a participant acquired soap is the relevant policy question - and because early termination could be an endogenous response to experimental treatments. As a robustness check, column 3 omits the 22 participants whose interviews ended before their soap decision. Again, coefficients are similar and the interaction is greater in magnitude.

Regression equation 5 is a saturated linear conditional expectation. Because offer acceptance is binary, probit may also be appropriate, though it requires more assumptions. Column 5 fits a probit model to the regressors in column 1 and recovers similar marginal effects; again the estimate of the interaction coefficient is larger in absolute value.

Columns 4 and 6 are included to demonstrate robustness. They add fixed effects of villages and surveyors, within which randomization was stratified. Duflo et al. (2008) recommend "controlling for variables not affected by the treatment" when analyzing experiments. However, Freedman (2008b) establishes that, with covariates, the estimated coefficients on experimentally assigned variables are biased in finite samples, and the coefficient estimates for regression covariates are inconsistent; Freedman (2008a) confirms that bias extends to cases with multiple randomized treatment groups. I include columns 4 and 6 - where, once 
again, results are similar and stronger - as robustness checks, in case a reader expects them.

If ten percentage points is a robust point estimate of $\beta_{3}$, can we infer that the true value is probably positive? Given the collection of data by village, cluster robust standard errors are necessary. Indeed $\rho_{\varepsilon}$, the intracluster correlation of residuals, is $0.026 .{ }^{15}$ However, the asymptotic normality of clustered estimates is achieved as the number of clusters increases. Thirteen clusters is too few, and in finite samples clustered standard errors may be biased downward.

Table 7 reports results of alternative inference strategies. Inflating standard errors and using a $t$ distribution with reduced degrees of freedom all result in similar $p$-values. While not crucial to the result, one-sided $p$-values may be appropriate, as the theory predicted $\beta_{3}>0$.

Cameron et al. (2008) report Monte Carlo simulations of alternative tests for regression coefficients under clustering, including a specification with a binary dependent variable regressed on two interacted dummies. They find that even with as few clusters or fewer than in this experiment, inference with a wild cluster bootstrapped $t$ distribution has empirical size very close to its theoretical, asymptotic size. ${ }^{16}$ A bootstrapped $t$ distribution with 10,000 draws returns one- and two-sided $p$ values for $\hat{\beta}_{3}$ of 0.032 and 0.059 .

The last two rows of table 7 present further simple tests. For each cluster $\hat{\beta}_{3}^{c}$ is computed by estimating equation 5 using only data from that cluster. These 13 estimates form a new sample of independent observations. Ibragimov and Müller (forthcoming) show that if clusters are independent and if the parameter is normally distributed in each cluster, even with different variances, then a $t$ test on this sample of parameters by cluster is valid. These conditions are met: a simulation does not reject that $\hat{\beta}_{3}$ has a normal distribution. ${ }^{17}$ A $t$ test on this sample of 13 rejects that the estimates of $\beta_{3}$ are drawn from a population with mean zero, and a non-parametric signed rank test reaches the same conclusion.

Using point estimates from the intent-to-treat regression in column 1 of table 6 and the largest $p$-values found by any method conservatively and robustly finds that while the deliberation treatment had no effect at the low price, it increased acceptance by over ten percentage points at the high price, consistent with proposition 2's predictions.

\footnotetext{
${ }^{15}$ An ANOVA test that $\rho_{\varepsilon}$ is zero is rejected with $F=2.30$. The "design effect," counterfactually assuming equal cluster sizes, would be $\sqrt{1+\left(\frac{647}{13}-1\right) 0.026}=1.50$.

${ }^{16}$ Wild cluster bootstraps resample from residuals but randomly multiply half by -1 , in this case treating members of a cluster identically. Bootstrapping the $t$ rather than standard errors provides an asymptotic refinement relevant for this small sample.

${ }^{17}$ I randomly selected one of the 13 clusters and simulated 1,000 estimates of $\beta_{3}$ by uniformly randomly assigning each observation a residual from that cluster, with replacement. Kolmogorov-Smirnov $(p=0.899)$, Shapiro-Wilk $(p=0.472)$ and Shapiro-Francia $(p=0.377)$ tests all fail to reject a normal distribution.
} 


\subsubsection{Differences in wealth: Proposition 3}

To maximize sample size for the experiment, I collected few survey questions and was unable to observe wealth directly. ${ }^{18}$ The control questions asked about participants' native villages; because I would only have to add it to the treatment group and because I suspected it might be informative about adult women's wealth, I collected data on whether all participants live in their native village.

Proposition 3 predicts that the range of foregone profitable offers is larger and the $p^{*}$ thinking threshold is lower for poorer people. Under the ancillary assumption that women who live as adults in their native village are poorer on average, $\beta_{3}$ - the average effect of the treatment on the effect of a higher price - should be larger for participants who live in their native village.

Are female Kucchi villagers who live in their native village poorer? Rosenzweig and Stark (1989) explain that, especially for women, "migration in India is... predominantly a marital phenomenon, for which conventional employment-based explanations of migration, motivated by the incentives of spatial income differentials, would appear ill-suited." ${ }^{19}$ Married women typically live in their husband's native village. Therefore, the question is whether women who marry within their village (practicing village endogamy) are poorer than women who marry outside their village (practicing village exogamy).

I have not found data on Kutch, or even Gujarat. Rahman and Rao (2004) conclude that "village exogamy is the norm practiced by a majority of communities in" Uttar Pradesh and Karnataka, but is not universal (248). Bloch et al. (2004), using survey data from five rural districts of Karnataka, a state in south India, argue that village exogamous weddings are more expensive because signalling high status through conspicuous consumption is possible; when marriage is within a village, there is less opportunity to change perceived status. In their data, exogamous marriages cost about 1,600 more rupees. More expensive weddings may be consumed by richer families.

Desai and Rao (1995) provided the data used in these studies. In analysis reported in appendix C, I find that adult women living in the village where they lived before marriage belong to poorer households. The difference is large: twenty-three percent of average annual income. This association is found with several measures of wealth and specifications. Though it describes Uttar Pradesh and Karnataka, it indicates that women in my sample living in

\footnotetext{
${ }^{18}$ Interviews were conducted by local graduate students who were required to be finished by the start of their examination period; I initially believed a wealth module would make the survey too long, and settled for village endogamy as a proxy.

${ }^{19}$ Rosenzweig and Stark (1989) disagree with models arguing that richer families can afford a geographically broader search for marriage partners, instead arguing that families use marriage as insurance, so rich families can afford nearer marriages. This conclusion is empirically mixed in their results.
} 
their native village may indeed be poorer.

Is, then, the interaction term larger for women who still live in their native village? Figure 6 indicates that it is. While in neither case does the thinking treatment have much effect at three rupees, at fifteen rupees it has a much larger effect among women who live where they were born.

Table 8 confirms this difference. Among women who are not reported to live in their native village, the interaction term is 7.2 percentage points; among women who do, it is 29.2 percentage points. Column 3 verifies that this 22 percentage point difference-in-differencein-differences is statistically distinguishable from zero. A wild cluster bootstrapped $t(b=$ 1,500 ) returns one- and two-sided $p$-values of 0.025 and 0.056 .

The experimental assignment of treatments does nothing to support my interpretation of residence as indicating a causal effect of wealth; it must be advocated with econometrics. However, only little additional data was observed; this limits my ability to include control variables but also confirms I had little scope to search among specifications.

What counfounds may be omitted? Women who live in their native village may have narrower exposure and therefore have been more skeptical of the soap or the surveyors in a way that the thinking treatment helped resolve. Alternatively, they may derive more autonomy and power from the nearness of native family. These individual differences in exposure or power may be also associated with whether a participant ever went to school. Adding schooling in column 4 may mitigate any bias from omitted insularity or autonomy. The estimate of the triple difference - the difference between $\hat{\beta}_{3}^{\text {poor }}$ and $\hat{\beta}_{3}^{\text {rich }}-$ does not change.

Some villages may be more likely to retain those who are born there: larger villages, for example. People who live in these villages may have different private values for soap or be otherwise different in ways other than being poorer. Column 5 includes village fixed effects. These are jointly significant, but only increase the estimate of the triple difference.

In section 3.3.3 I will consider whether a woman has children and whether she reports a child having had diarrhea in the prior week as indicators of her value for soap. These, too, could differ for those who live in their native villages, though they might over-control if they are also caused by poverty. Additionally, though with the concerns discussed in section 3.2.1, participants were asked whether they bought soap last time they went to the market (richer participants perhaps already have a stock of soap). Including all three as controls in column 6 does not change the triple difference.

The interaction between the effects on acceptance of the higher price and of the thinking treatment is greater for participants reported to live in their native village than those who 
are not. If a woman's living in her native village as an adult indicates poverty ${ }^{20}$ this finding is consistent with proposition 3. The interpretation of residence as wealth is supported by the fact that controlling for plausible alternative explanations only increases the magnitude of the estimate of the triple difference, without loss of precision.

\subsubsection{Bounded rationality and screening}

A consistent finding of the social marketing experiments is that higher prices do not direct products to those who need them most, as these experiments measure need. For example, Cohen and Dupas (2007) find that those who buy bednets at a higher price have no more anemia. Section 2.3 argues theoretically that deliberation costs could prevent prices from targeting distribution to those with the highest value. Is there evidence that this occurred in Kutch?

Figure 7 indicates that there is. I identify households with greater need for handwashing with soap as those with children and those where the participant reports at least one child having had a loose stool in the previous week. Like in prior experiments, where participants experienced unmanipulated deliberation costs, in the control group those who bought the soap at the higher price were no more likely to have children and no more likely to report diarrhea. In the treatment group, with no marginal deliberation costs, buyers at a higher price were needier by both measures.

Table 9 reports this result econometrically. In the treatment group, the higher price more than doubled the proportion of buyers who reported diarrhea, increasing it by 9.8 percentage points. Among participants asked control questions, charging fifteen rather then three rupees is associated with a statistically insignificant 2.8 percentage point decline in loose stools. Similarly, while charging a higher price is associated with only a statistically insignificant 1.3 percentage point increase in the fraction of buyers having children in the control group, in the treatment group it increases this fraction by 8.9 percentage points.

Columns 3 and 6 permit inference on the effect of eliminating deliberation costs on the screening effect of prices as an interaction. With the sample restricted to the 382 women who bought soap, coefficient estimates are relatively imprecise. For diarrhea, wild cluster bootstrap $t(b=1,500)$ one- and two-sided $p$-values for the interaction term are 0.027 and 0.049. For having children, these $p$-values indicate insufficient precision to rule out sampling error: 0.23 and 0.45 .

\footnotetext{
${ }^{20}$ Evidence potentially against this interpretation is that more participants living in their native village than participants not living in their native village accepted soap for three rupees. The difference is not statistically significant in any comparison.
} 
In the control group, as in prior experiments, there is no evidence of higher prices screening buyers. Without deliberation costs, however, higher prices made soap more likely to be bought by households where children had diarrhea, and perhaps more likely to be bought by households with children.

\section{Conclusion}

A stylized but tractable model of bounded rationality as deliberation costs can explain the findings of previous field experiments evaluating social marketing programs. Deliberation costs cause people to ignore potentially profitable offers, have effects weakly increasing in price, and can have greater effects on poorer people. The model's predictions were verified by a field experiment in villages of rural Kutch, India. By manipulating deliberation costs while selling a brand of soap used in a well-publicized social marketing campaign, the experiment identified these costs' effects.

\subsection{Theoretical implications}

Despite the theoretical challenges outlined by Conlisk (1996), a theory of bounded rationality can be usefully applied and make new, testable predictions. Gul and Pesendorfer (2008) emphasize that economic models should be based in empirical evidence of observable behavior, in the economic actions people take. Table 10 summarizes the evidence: unlike the predictions of models of emotional responses to discounts, social preferences (as experimenter demand), present bias, or standard unbounded rationality, this model's predictions were confirmed.

Holla and Kremer (2009) recognize that cost-sharing prices are "relatively small shortrun costs;" this understandably suggests to Holla and Kremer that the findings of prior social marketing experiments may be explained by time-inconsistent preferences. Present biased behavior is surely widespread, and it is reasonable to suspect it here, but models of present biased preferences may sometimes be applied to behavior better explained by bounded rationality. Frederick (2005), Benjamin et al. (2006), and Dohmen et al. (2007) all report evidence that cognitive ability is associated with impatience, as commonly measured.

This model can be readily applied to other domains, especially where $\pi$, the trustworthiness of initial signals, is likely to be low. For example, while Ergin suggests deliberation costs may influence shoppers' choices of car dealerships (that is, choice sets), such costs may lead some people to avoid contemplating a new car at all.

The results suggest that "behavioral" and non- "behavioral" economics perhaps should 
not be considered two parallel but separate lines of inquiry, with one group of scholars focusing on "psychological" variables and another on "economic" variables such as prices and wealth ( $c f$. Caplin and Schotter, 2008). Whether a person buys at a price partially depends on whether she thinks carefully about the offer, which itself depends on the price. Prices and cognition interact; among Kucchi villagers, a theorist would understand neither without understanding them together.

\subsection{Policy implications}

Social marketing is popular. Neath (2006) reports of Unilever's effort that "by 2005 the campaign had reached 18,000 villages and touched 70 million people, including 20 million children... . Based on our experience in India, the Lifebuoy handwash programme has been extended to Bangladesh."

Like microentrepreneurship, cost sharing is endorsed by some because it offers a marketbased solution, and by others for "homegrown" empowerment of the poor to make and fulfill choices about their health and education (Shea, 2007). Certainly poverty's diminution of choice can be profound. But the cognitive capabilities of the rich and the poor shape - and may limit - the benefits of empowered choice ( $c f$. Banerjee and Duflo, 2008).

This essay confirms and contributes to explaining findings from previous experiments: charging even small, subsidized prices for investments in human capital can markedly diminish adoption without screening out recipients who do not need products. While these experiments have suggested cost sharing will not reach its policy goals in a range of contexts, Holla and Kremer, Deaton, and Rodrik agree that the results would be most usefully generalized for policy-making with a theoretical explanation. If bounded rationality as deliberation costs indeed provides one explanation, free distribution of certain products may be preferable to social marketing wherever people are boundedly rational.

\section{A Proofs \& computations}

\section{A.1 Proof of Proposition 3}

The first claim follows from the inequality defining $p^{*}$ in 3 and the implicit function theorem.

$$
\frac{\partial p^{*}}{\partial w}=-\frac{(1-\pi) v_{w}}{(1-\pi) v_{p}}=-\frac{-}{+}>0 .
$$

Let two agents have $w_{\ell}<w_{h}$. Denote the area of the set of profitable offers forgone as $\mathcal{L}$. 
The second claim follows by dividing the range of prices into three regions: less than $p^{*}\left(w_{\ell}\right)$, between $p^{*}\left(w_{\ell}\right)$ and $p^{*}\left(w_{h}\right)$, and above $p^{*}\left(w_{h}\right)$.

$$
\begin{aligned}
\mathcal{L}_{\ell}-\mathcal{L}_{h} & =\int_{0}^{p^{\max }}\left(\bar{x}^{B R}\left(p, w_{\ell}\right)-\bar{x}\left(p, w_{\ell}\right)\right) d p-\int_{0}^{p^{\max }}\left(\bar{x}^{B R}\left(p, w_{h}\right)-\bar{x}\left(p, w_{h}\right)\right) d p . \\
& =\left[\int_{0}^{p^{*}\left(w_{\ell}\right)}\left(\bar{x}^{B R}\left(p, w_{\ell}\right)-\bar{x}\left(p, w_{\ell}\right)\right) d p-\int_{0}^{p^{*}\left(w_{\ell}\right)}\left(\bar{x}^{B R}\left(p, w_{h}\right)-\bar{x}\left(p, w_{h}\right)\right) d p\right] \\
& +\left[\int_{p^{*}\left(w_{\ell}\right)}^{p^{*}\left(w_{h}\right)}\left(\bar{x}^{B R}\left(p, w_{\ell}\right)-\bar{x}\left(p, w_{\ell}\right)\right) d p-\int_{p^{*}\left(w_{\ell}\right)}^{p^{*}\left(w_{h}\right)}\left(\bar{x}^{B R}\left(p, w_{h}\right)-\bar{x}\left(p, w_{h}\right)\right) d p\right] \\
& +\left[\int_{p^{*}\left(w_{h}\right)}^{p^{\max }}\left(\bar{x}^{B R}\left(p, w_{\ell}\right)-\bar{x}\left(p, w_{\ell}\right)\right) d p-\int_{p^{*}\left(w_{h}\right)}^{p^{\max }}\left(\bar{x}^{B R}\left(p, w_{h}\right)-\bar{x}\left(p, w_{h}\right)\right) d p\right] .
\end{aligned}
$$

Above $p^{*}\left(w_{h}\right)$, both agents' set of foregone offers have the area of a rectangle of height $\frac{c}{\pi}$ and width $p^{\max }-p^{*}\left(w_{h}\right)$; therefore the third term is zero (even if $p^{\max }=\infty$ ). In the second term, the height of the poorer agent's set is $\frac{c}{\pi}$ at every price, while the richer agent's set has not yet achieved this maximum height; because the poorer agent's set is wider at every price, the second term is positive. In the first term, at every price the height of each agent's set is $(\gamma-1) v(p, w)$; because $v_{w}<0$, this is higher at each price for the poorer agent and the first term is positive. The sum of two positive quantities and zero is positive. Thus, the area of the set of foregone positive offers is lower for the agent with more wealth.

\section{A.2 Proof of Proposition 4}

The first and second claims follows from the inequality defining $p^{*}$ in 3 and the implicit function theorem.

$$
\begin{aligned}
& \frac{\partial p^{*}}{\partial c}=-\frac{-1}{(1-\pi) v_{p}}=-\frac{-}{+}>0 . \\
& \frac{\partial p^{*}}{\partial \pi}=-\frac{-v(p, w)}{(1-\pi) v_{p}}=-\frac{-}{+}>0 .
\end{aligned}
$$

For convergence as $c \rightarrow 0$, fix any $\epsilon>0$. For all $p, \bar{x}^{B R}-\bar{x} \leq \frac{c}{\pi}$. Let $c^{*}=\pi \epsilon$. Then, for all $c<c^{*}, \bar{x}^{B R}-\bar{x}<\epsilon$ at any $p$.

For convergence as $\pi \rightarrow 1$, fix any $\epsilon>0$ and any $p$. If $c \leq \epsilon$, let $\pi^{*}>\frac{c}{\epsilon}$; then, because for all $p, \bar{x}^{B R}-\bar{x}<\frac{c}{\pi}$, for all $\pi>\pi^{*} \bar{x}^{B R}-\bar{x}<\epsilon$. Otherwise let $\gamma^{*}=\frac{\epsilon+v(p, w)}{v(p, w)}$ Clearly $\gamma^{*}<1$ and converges to 1 as $\epsilon$ becomes small. Whether bounded rationality concerns $x$, so $\gamma=\frac{1}{\pi}$, or $u(\cdot)$, so $\gamma=\pi+(1-\pi) \lambda, \gamma$ is decreasingly converging to 1 as $\pi$ increasingly converges to 1. Set $\pi^{*}$ such that $\pi>\pi^{*}$ implies $\gamma>\gamma^{*}$. If $\pi>\pi^{*}$, then

$$
\bar{x}^{N T}-\bar{x}=(\gamma-1) v(p, w)<\epsilon<c<\frac{c}{\pi}
$$

and therefore $p<p^{*}$, so $\bar{x}^{B R}-\bar{x}<\epsilon$. 


\section{A.3 Computation of arc elasticities}

Except for water disinfectant, all figures are midpoint arc elasticities (Allen and Lerner, 1934), calculated from the largest available spread of two positive prices.

- Holla and Kremer write in their table 1 that, for deworming when "charging an average of $\$ 0.30 /$ child for deworming medicine," "relative to free treatment, take-up drops by 62 percentage points $(82 \%) . " 62 \div 0.82=75.61 ; 75.61-62=13.61 \cdot \frac{0+0.3}{13.61+75.61} \frac{62}{.3}=.6949$.

- About bednets, on page 9 Holla and Kremer write: "In the clinics that offered free nets, take-up was 99 percent. Relative to this rate, take-up in clinics that charged for the nets declined at an increasing rate as prices moved from $10 \ldots$ to $40 \mathrm{Ksh}$.. by $7.3, \ldots$ and 60.5 percentage points respectively." $\frac{10+40}{(99-7.3)+(99-60.5)} \frac{60.5-7.3}{40-10}=0.384 \times 1.773=0.681$.

- For disinfectant, in table 1 Holla and Kremer report "estimated price elasticity of -0.6."

- For this experiment's control group, $\frac{3+15}{29.8+84.0} \frac{84.0-29.8}{12}=0.1582 \times 4.517=0.714$.

- For the treatment group, $\frac{3+15}{39.0+82.4} \frac{82.4-39.0}{12}=0.1483 \times 3.617=0.536$. 


\section{B Experimental text}

\begin{tabular}{|c|c|c|c|}
\hline Number & Thinking Questions & Control Questions & Match \\
\hline & & $\begin{array}{l}\text { What is the nearest village to } \\
\text { this one? }\end{array}$ & \\
\hline 1 & $\begin{array}{l}\text { Will this soap last for more } \\
\text { than } 10 \text { days, or will it be fin- } \\
\text { ished before that? }\end{array}$ & $\begin{array}{l}\text { Will you go to } x \text { village in the } \\
\text { next } 10 \text { days? }\end{array}$ & 1 \\
\hline 2 & $\begin{array}{l}\text { Could you buy this much soap } \\
\text { at a lower price in the market? }\end{array}$ & $\begin{array}{l}\text { Which of the two villages has } \\
\text { more people? }\end{array}$ & 2 \\
\hline 3 & $\begin{array}{l}\text { If you buy this soap, will you } \\
\text { buy soap the next time you go } \\
\text { to the market? }\end{array}$ & $\begin{array}{l}\text { How would you go to } x \text { village } \\
\text { if you had to get there in a } \\
\text { hurry? }\end{array}$ & 3 \\
\hline 4 & $\begin{array}{l}\text { How much flour could you buy } \\
\text { for } p \text { rupees? }\end{array}$ & $\begin{array}{l}\text { Is } x \text { village less than } 10 \mathrm{~km} \\
\text { from here? }\end{array}$ & 5 \\
\hline 5 & $\begin{array}{l}\text { Could you buy a bucket for } p \\
\text { rupees? }\end{array}$ & $\begin{array}{l}\text { How much time do you spend } \\
\text { cooking each day? }\end{array}$ & 4 \\
\hline 6 & $\begin{array}{l}\text { Will you need the } p \text { rupees for } \\
\text { something else in the next } 10 \\
\text { days? }\end{array}$ & $\begin{array}{l}\text { When will the rain come to } \\
\text { your village this year? }\end{array}$ & 6 \\
\hline 7 & $\begin{array}{l}\text { If you do not buy the soap, } \\
\text { on what will your household } \\
\text { spend the } p \text { rupees? }\end{array}$ & $\begin{array}{l}\text { If the rain did not come this } \\
\text { year, what would people in } \\
\text { your village do? } \\
\text { What is your native village? }\end{array}$ & 7 \\
\hline 8 & $\begin{array}{l}\text { Please say one reason why tak- } \\
\text { ing this soap would be a good } \\
\text { idea for you. }\end{array}$ & $\begin{array}{l}\text { Please say one reason you } \\
\text { would like living in your native } \\
\text { village. }\end{array}$ & 8 \\
\hline 9 & $\begin{array}{l}\text { Please say one reason why tak- } \\
\text { ing this soap would be a bad } \\
\text { idea for you. }\end{array}$ & $\begin{array}{l}\text { Please say one reason you } \\
\text { would not like living in your } \\
\text { native village. }\end{array}$ & 9 \\
\hline
\end{tabular}

The translations were tested, edited, and revised many times, but they were necessarily approximate. For example, there are no articles in Gujarati; the future conditional subjunctive tense was not familiar to Kucchi villagers. Because surveyors were trained to follow the script precisely, special care was taken to achieve simple phrasing that would be comprehensible to this population.

In the thinking treatment, before asking the questions the surveyor said:

First, I would like to talk with you about soap. Washing with soap helps keep people healthy. [A] college gave me this soap. It is my project. This package contains 2 bars of soap. Later on, you may have the package of soap for $p$ rupees. It will be up to you whether you want to take the soap or not. Before you decide 
whether to take the soap, I will ask you some questions.

After the thinking questions the surveyor reminded the participant, "remember, you may have the package of soap for $p$ rupees." In the control treatment, the surveyor gave no special introduction to the control questions but read the same text (without "later on") after the control questions, immediately before the soap decision. Then, participants in both treatments were asked "would you like to buy the soap now for $p$ rupees?". Surveyors were trained to wait for the participant to decide and not to proceed to other survey questions until she had reported her decision. They were further trained to not pressure participants or interfere with participants' decisions.

\section{Village endogamy and poverty}

Vijayendra Rao kindly provided the data used by Bloch et al. (2004) and Rahman and Rao (2004), which contains information on household wealth, endogamy norms, and where wives lived before marriage (Desai and Rao, 1995). ${ }^{21}$ The data are from "five districts in Karnataka in South India and five districts in Uttar Pradesh in the North," and are "based on 800 complete responses to a household survey provided by married women... . The survey, conducted in 1995, was administered to 1,120 households, which contained 1,897 women of reproductive age" (Rahman and Rao, 2004, 244).

Are adult women who live in the same village that they lived in before they were married poorer than those who do not? Table 12 indicates they are. I use three measures of wealth: total annual household income, the number of assets in a list that the household owns, ${ }^{22}$ and whether the household owns any agricultural land. For all three measures, a woman living in her home village is associated with her household having less wealth, a result that also holds restricting income observations to only respondents who claimed not to be guessing. Except in the case of owning agricultural land, the relationship is even stronger focusing only on Uttar Pradesh, which is in the north of India and may be more similar to Gujarat. This finding is robust to controlling for district fixed effects, whether the woman has ever attended school, and whether she reports belonging to a subcaste that traditionally practices village endogamy.

\footnotetext{
21 "The survey from which these data are obtained was conducted under the supervision of Sonalde Desai and Vijayendra Rao, under the aegis of the Institute for Social Studies Trust with a grant from the Rockefeller Foundation. Data collection was conducted by NCAER in 1995."

${ }^{22}$ This is a discrete count ranging from 0 to 14, to which I fit a Poisson model. Case et al. (2004) uses a similar metric ("The index of durables is simply the sum of the number of kinds of durables the household owned.") to measure wealth in African households.
} 


\section{References}

Allen, R. G. D. and A. P. Lerner. 1934. "The Concept of Arc Elasticity of Demand." The Review of Economic Studies, 1(3): 226-230.

Ashraf, Nava, James N. Berry, and Jesse M. Shapiro. 2007. "Can Higher Prices Stimulate Product Use? Evidence from a Field Experiment in Zambia." NBER Working Paper W13247.

Banerjee, Abhijit V. and Esther Duflo. 2008. "Mandated Empowerment: Handing Antipoverty Policy Back to the Poor?" Annals of the New York Academy of Sciences, 1136: $333-341$.

Baumol, William J. and Richard E. Quandt. 1964. "Rules of Thumb and Optimally Imperfect Decisions." American Economic Review, 54(1): 23-46.

Bem, Darly J.. 1967. "Self-perception: An Alternative interpretation of cognitive dissonance phenomena." Psychological Review, 74(3): 183-200.

Benjamin, Daniel J., Sebastian A. Brown, and Jesse M. Shapiro. 2006. "Who is 'Behavioral'? Cognitive Ability and Anomalous Preferences." working paper, Harvard University.

Bertrand, Marianne, Sendhil Mullainathan, and Eldar Shafir. 2005. "A Behavioral Economics View of Poverty." mimeo, Harvard and Princeton.

Bloch, Francis, Vijayendra Rao, and Sonalde Desai. 2004. "Wedding Celebrations as Conspicuous Consumption: Signaling Social Status in Rural India." The Journal of Human Resources, 39(3).

Cameron, A. Colin, Jonah B. Gelbach, and Douglas L. Miller. 2008. "BootstrapBased Improvements for Inference with Clustered Errors." The Review of Economics and Statistics, 90(3): 414-427.

Caplin, Andrew and Andrew Schotter. eds. 2008. The Foundations of Positive and Normative Economics: Oxford.

Case, Anne, Christina Paxson, and Joseph Ableidinger. 2004. "Orphans in Africa: Parental Death, Poverty, and School Enrollment." Demography, 41(3).

Cohen, Jessica and Pascaline Dupas. 2007. "Free Distribution vs. Cost-Sharing: Evidence from a Malaria-Prevention Field Experiment in Kenya." Brookings Institution Global Economy and Development Working Paper.

Conlisk, John. 1996. "Why Bounded Rationality?" Journal of Economic Literature, 34: 669-700.

Deaton, Angus. 2009. "Instruments of development: Randomization in the tropics and the search for the elusive keys to development." keynes lecture, British Academy. 
Desai, Sonalde and Vijayendra Rao. 1995. "UP-Karnataka Gender, Marriage and Kinship Survey." unpublished data, Institute for Social Studies Trust.

Dohmen, Thomas, Armin Falk, David Huffman, and Uwe Sunde. 2007. "Are Risk Aversion and Impatience Related to Cognitive Ability?" Discussion Paper 2735, IZA.

Duflo, Esther, Rachel Glennerster, and Michael Kremer. 2008. "Using randomization in developent economics research: A toolkit." in Handbook of Development Economics, 4: Elsevier: 3895-3962.

Dupas, Pascaline. 2009. "What Matters (and What Does Not) in Households' Decisions to Invest in Malaria Prevention?" Americen Economic Review Papers and Proceedings.

Easterly, Willam. 2006. "Planners versus Searchers in Foreign Aid." Asian Development Review, 23(1): 1-35.

Ergin, Haluk. 2003. "Costly Contemplation." mimeo, MIT.

Fischhoff, Baruch. 1982. "Debiasing." in D. Kahneman, P. Slovic, and A. Tversky eds. Judgment under uncertainty: Heuristics and biases: Cambridge: 422-444.

Frederick, Shane. 2005. "Cognitive Reflection and Decision Making." Journal of Economic Perspectives, 19(4).

Freedman, David A.. 2008a. "On regression adjustments in experiments with several treatments." The Annals of Applied Statistics, 2(1): 176-196.

Freedman, David A. 2008b. "On regression adjustments to experimental data." Advances in Applied Mathematics, 40: 180-93.

Gul, Faruk and Wolfgang Pesendorfer. 2008. "The Case for Mindless Economics." in Andrew Caplin and Andrew Schotter eds. The Foundations of Positive and Normative Economics: Oxford.

Holla, Alaka and Michael Kremer. 2009. "Pricing and Access: Lessons from Randomized Evaluations in Education and Health." Center for Global Development Working Paper 158.

Ibragimov, Rustam and Ulrich K. Müller. forthcoming. "t-statistic Based Correlation and Heterogeneity Robust Inference." Journal of Business and Economic Statistics.

Kosek, Margaret, Caryn Bern, and Richard L. Guerrant. 2003. "The global burden of diarrhoeal disease, as estimated from studies published between 1992 and 2000." Bulletin of the World Health Organization, 81: 197-204.

Kremer, Michael and Edward Miguel. 2007. "The Illusion of Sustainability." Quarterly Journal of Economics, 112(3): 1007-1065.

Kreps, David M.. 1990. Game Theory and Economic Modelling, Oxford: Clarendon.

Luby, Stephen P., Mubina Agboatwalla, John Painter Arshad Altaf, Ward L. Billhimer, and Robert M. Hoekstra. 2004. "Effect of Intensive Handwashing Promotion on Childhood Diarrhea in High-Risk Communities in Pakistan: A Randomized 
Controlled Trial." Journal of the American Medical Association, 291(21): 2547-2554.

Neath, Gavin. 2006. "Business as a Partner in Reaching the Millennium Development Goals." conference paper, The Business, NGO, and Development Conference. World Bank.

Rahman, Lupin and Vijayendra Rao. 2004. "The Determinants of Gender Equity in India: Examining Dyson and Moore's Thesis with New Data." Population and Development Review, 30(2): 239268.

Rodrik, Dani. 2008. "The New Development Economics: We Shall Experiment, but How Shall We Learn?" what works in development: Thinking big and thinking small conference, Kennedy School of Government.

Rosenzweig, Mark R. and Oded Stark. 1989. "Consumption Smoothing, Migration, and Marriage: Evidence from Rural India." The Journal of Political Economy, 97(4): 905-926.

Rubinstein, Ariel. 1998. Modeling Bounded Rationality, Cambridge: MIT.

Schwarz, Norbert, Lawrence J. Sanna, Ian Skurnik, and Carolyn Yoon. 2007. "Metacognitive experiences and the intricacies of setting people straight: Implications for debiasing and public information campaigns." Advances in Experimental Social Psychology, 39: 127-161.

Shampanier, Kristina, Nina Mazar, and Dan Ariely. 2007. "Zero as a Special Price: The True Value of Free Products." Marketing Science, 26(6): 742-757.

Shea, Christopher. 2007. "A handout, not a hand up: A popular approach to "sustainable development' doesn't work, critics say." The Boston Globe, November 11.

Simon, Herbert A.. 1957. Models of Man, New York: Wiley.

Spence, Michael and Richard Zeckhauser. 1972. "The Effect of the Timing of Consumption Decisions and the Resolution of Lotteries on the Choice of Lotteries." Econometrica, 40(2): 401-403.

Zwane, Alix Peterson and Michael Kremer. 2007. "What Works in Fighting Diarrheal Diseases in Developing Countries?: A Critical Review." The World Bank Research Observer, 22(1): 1-24. 


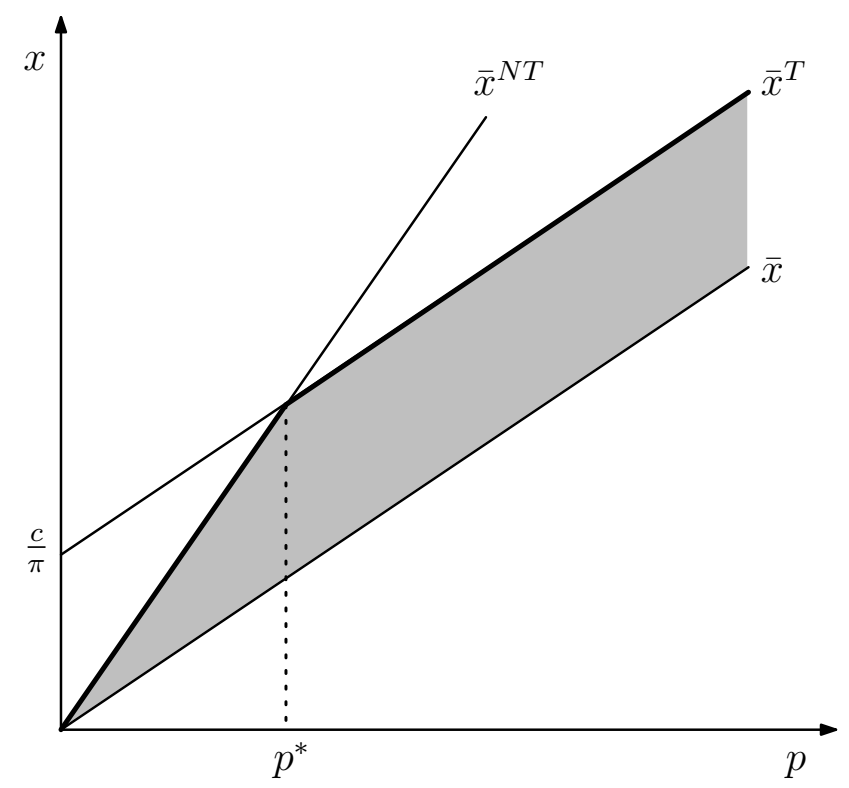

Figure 1: Boundedly rational buying behavior

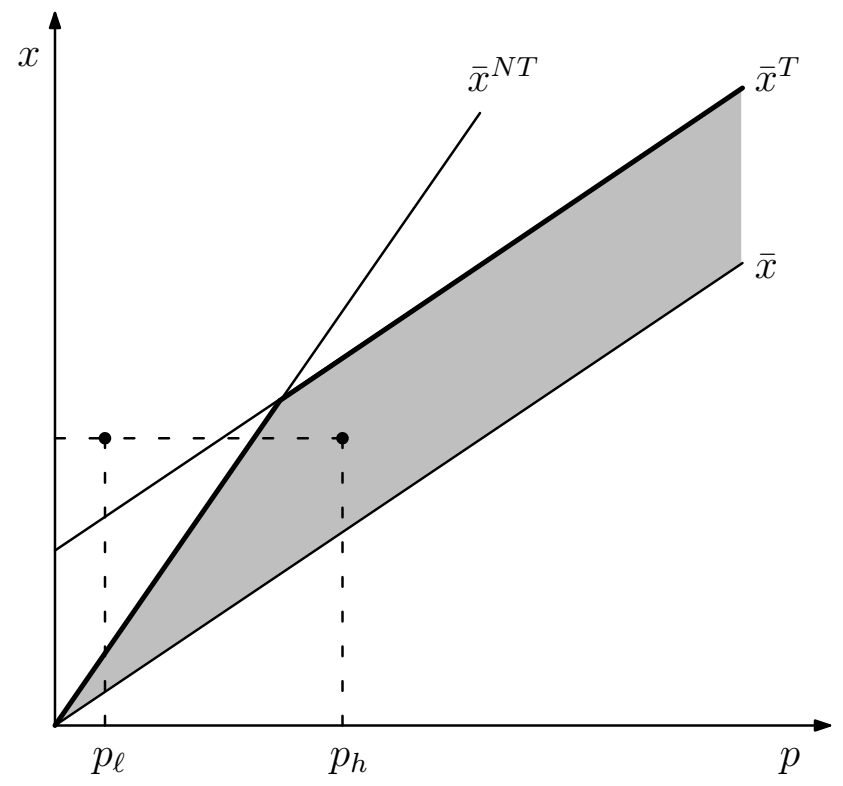

Figure 2: Eliminating deliberation costs at high and low prices 


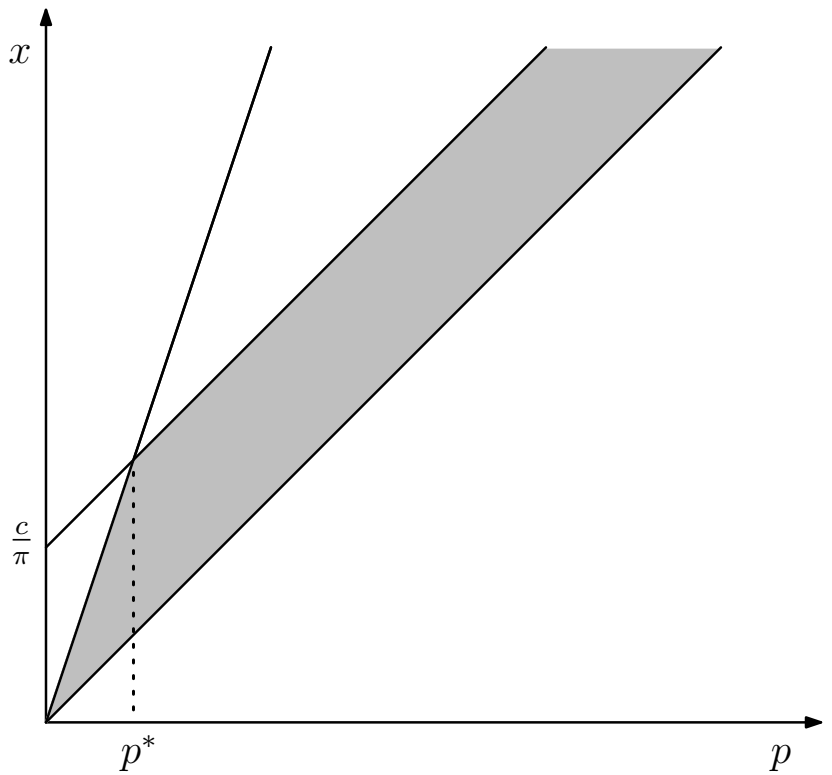

(a) poor

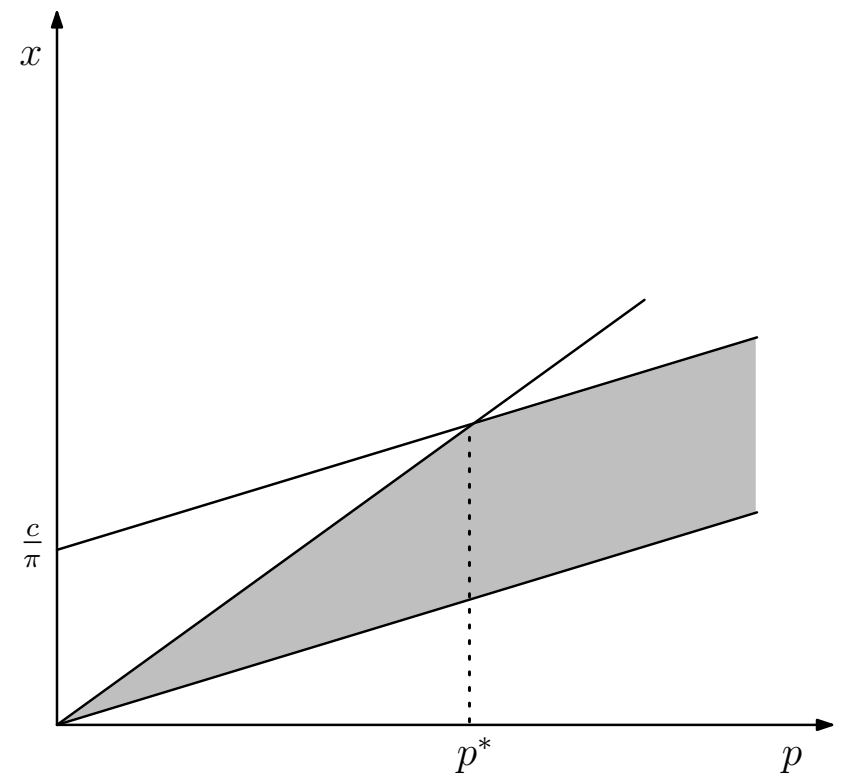

(b) rich

Figure 3: Deliberation costs, foregone offers, and wealth 


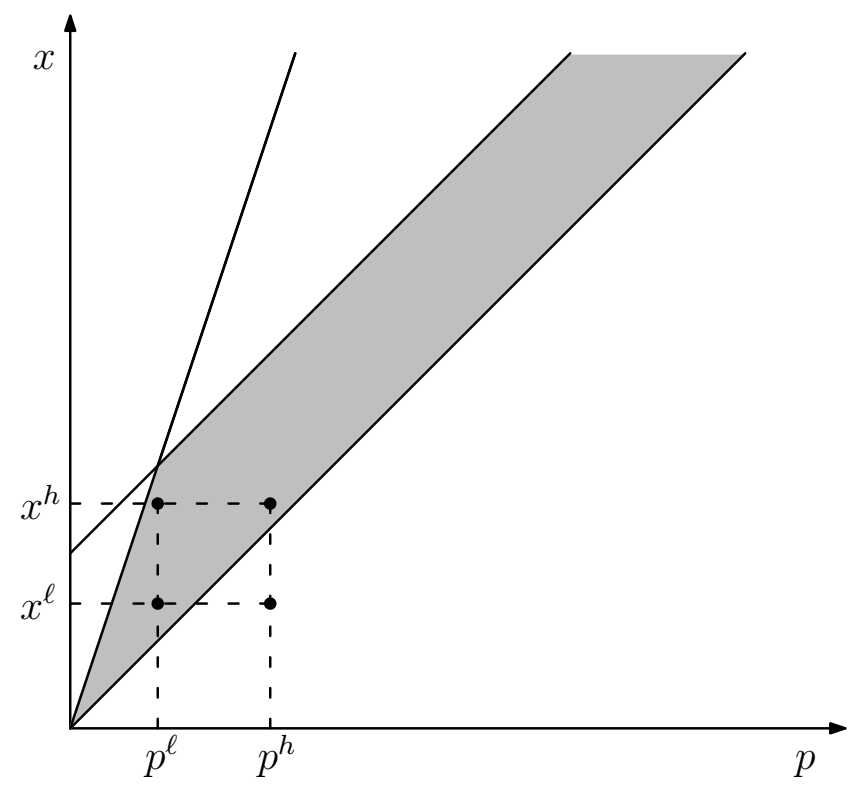

Figure 4: Deliberation costs suppress screening

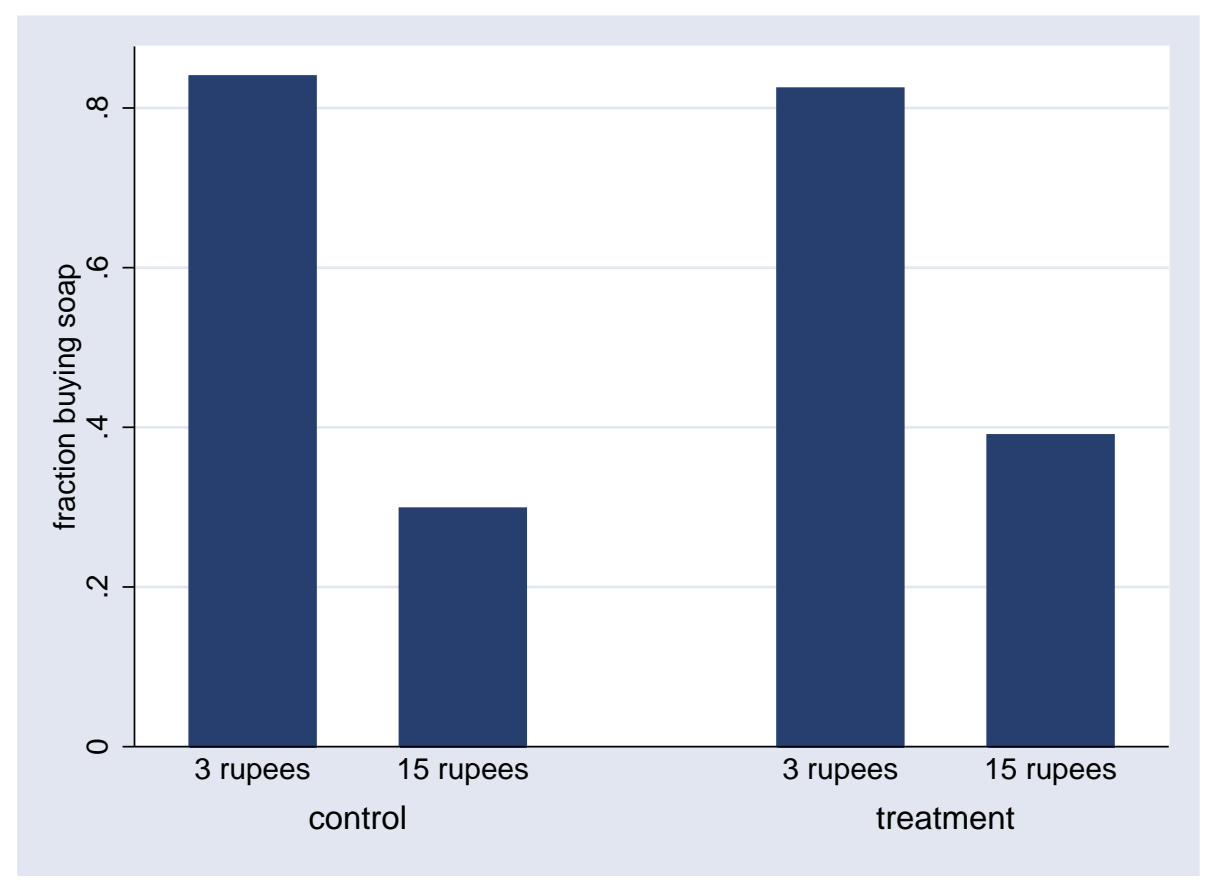

Figure 5: Fraction buying soap by experimental treatment 


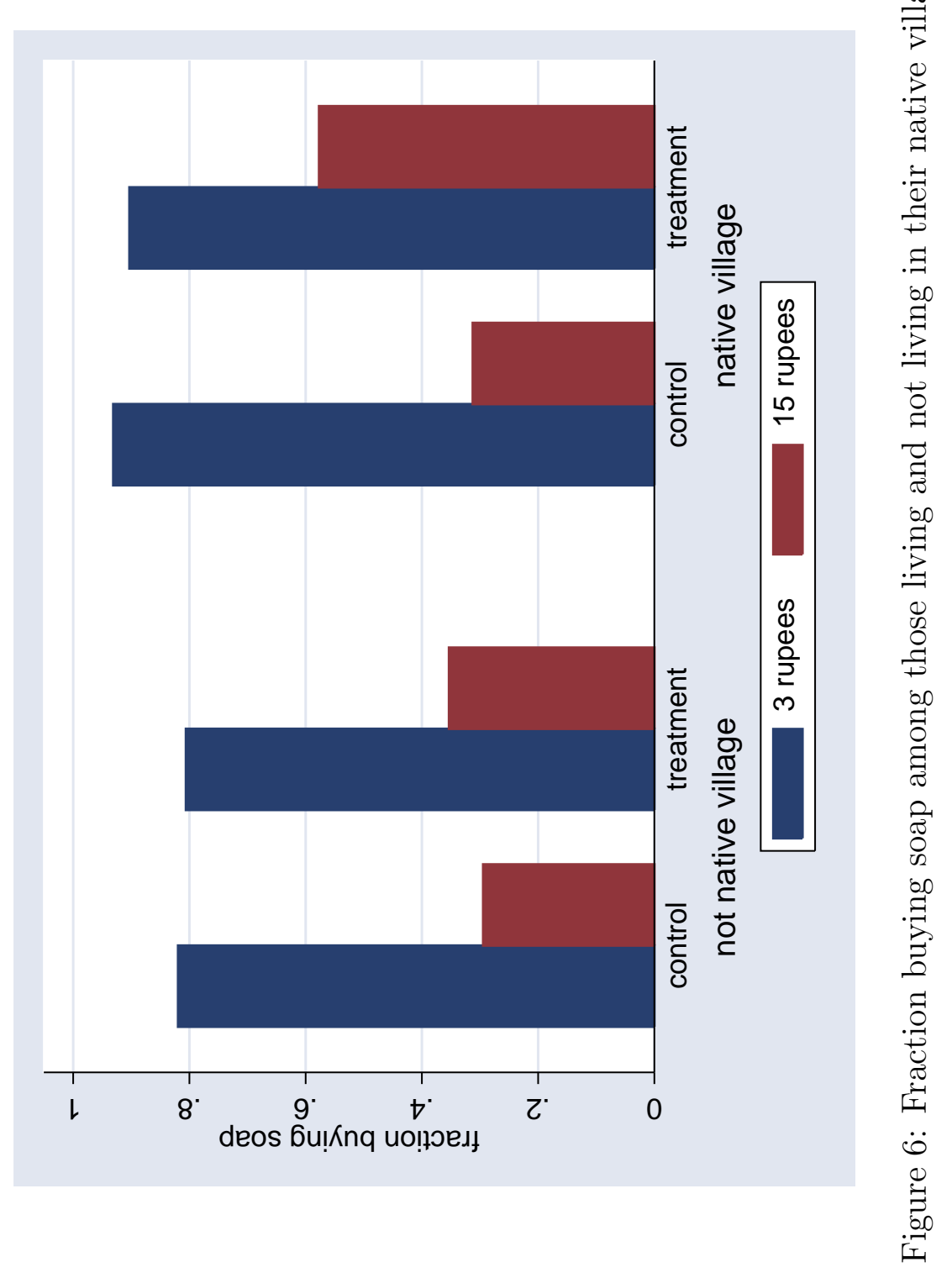




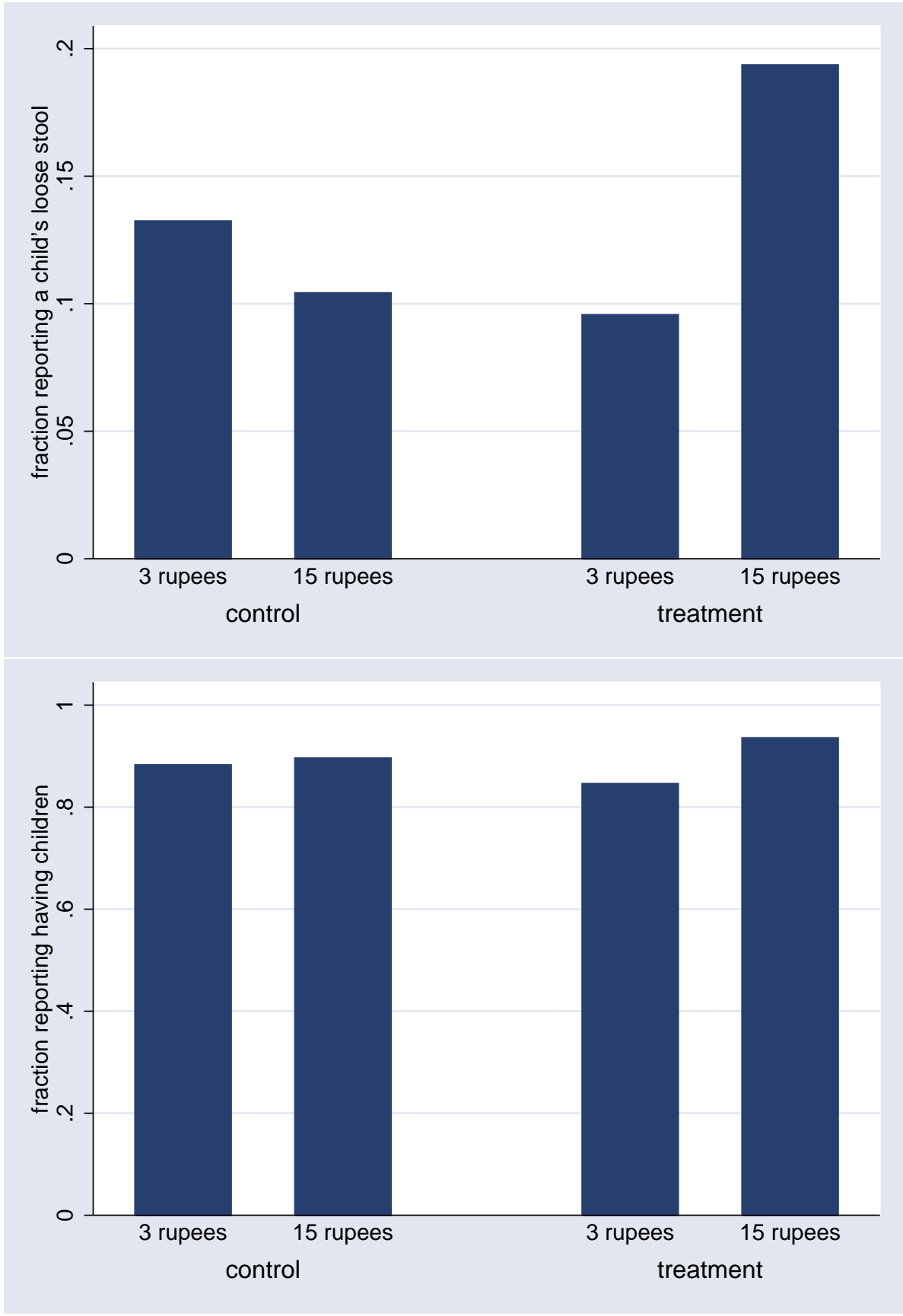

$$
n=382 \text {. }
$$

Figure 7: Screening among those who bought soap, by experimental treatment 
Table 4: Prices and weights of hand and body soap found in experimental villages

\begin{tabular}{|c|c|c|c|c|}
\hline soap & grade & price $(\mathrm{Rs})$ & weight $(\mathrm{g})$ & $\mathrm{Rs} / \mathrm{g}$ \\
\hline Experiment: $p_{\ell}$ & 3 & 3 & 240 & 0.013 \\
\hline Experiment: $p_{h}$ & 3 & 15 & 240 & 0.063 \\
\hline Nima & 1 & 7 & 75 & 0.093 \\
\hline Nirma: Premium & 1 & 12 & 125 & 0.096 \\
\hline Nirma: Pink & 1 & 9 & 92 & 0.098 \\
\hline Dyna: Lime \& Aloe Vera & 1 & 5 & 50 & 0.100 \\
\hline Dyna: Sandal \& Saffron & 1 & 5 & 50 & 0.100 \\
\hline Nirma: Pink & 1 & 5 & 50 & 0.100 \\
\hline Dyna: Milk \& Almond & 1 & 10 & 100 & 0.100 \\
\hline Ruchi Health & & 10 & 100 & 0.100 \\
\hline Jo & 2 & 12 & 115 & 0.104 \\
\hline Lifebuoy & 3 & 13 & 120 & 0.108 \\
\hline Lifebuoy Swasthya Chetna & & 2 & 18 & 0.111 \\
\hline No. 1 & 1 & 10 & 90 & 0.111 \\
\hline Vatika & 2 & 12 & 100 & 0.120 \\
\hline Medimix & & 5 & 40 & 0.125 \\
\hline Fair One & 1 & 10 & 75 & 0.133 \\
\hline Lifebuoy & 3 & 12 & 90 & 0.133 \\
\hline Vivel & 2 & 16 & 116 & 0.138 \\
\hline Medimix & & 20 & 125 & 0.160 \\
\hline Lux & 2 & 10 & 54 & 0.185 \\
\hline Hamam & 3 & 17 & 90 & 0.189 \\
\hline Liril & 2 & 18 & 75 & 0.240 \\
\hline Dettol & 2 & 18 & 70 & 0.257 \\
\hline EZY & & 21 & 80 & 0.263 \\
\hline Dettol & 2 & 19 & 70 & 0.271 \\
\hline
\end{tabular}




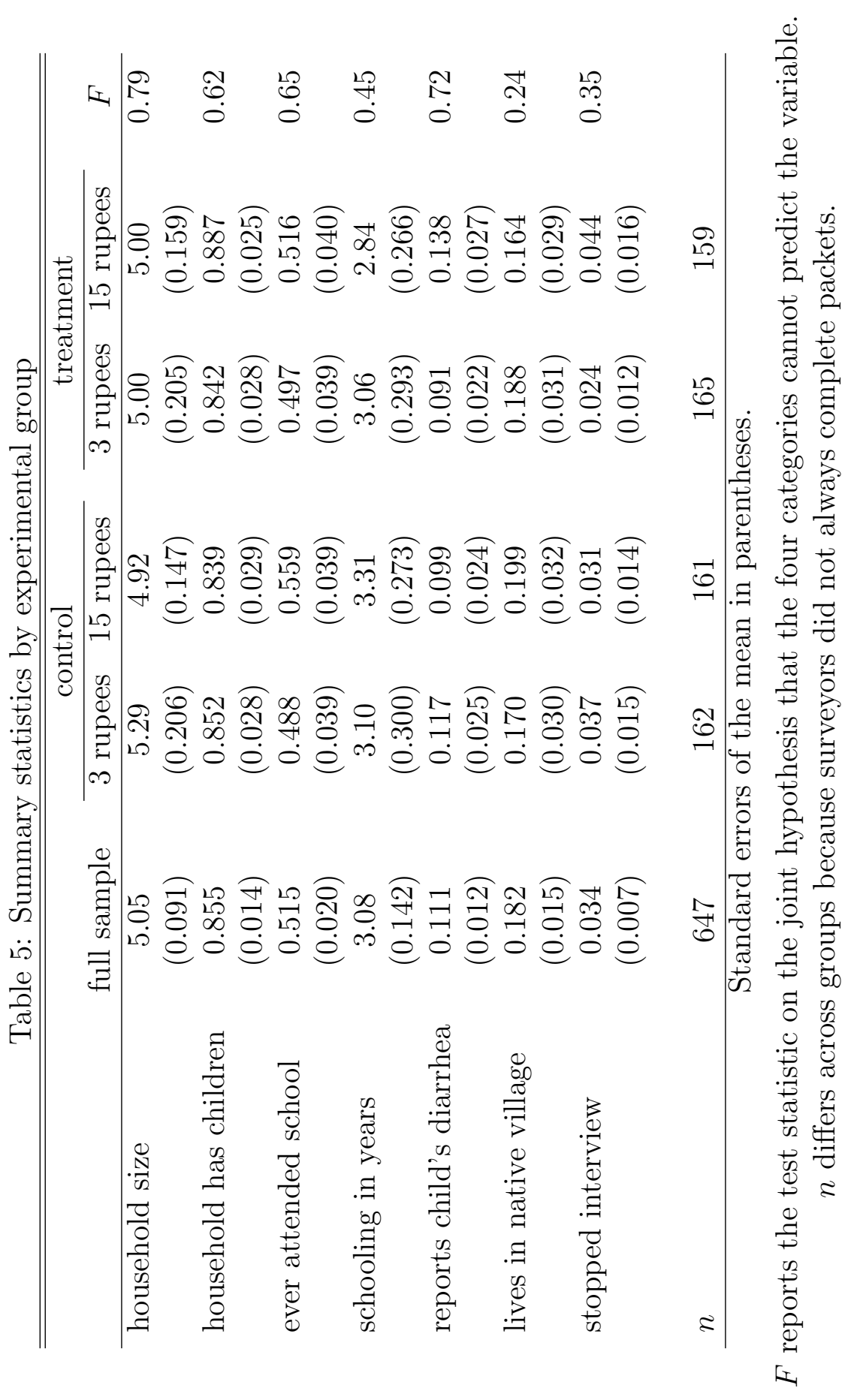


Table 6: Probability of buying soap by experimental group

\begin{tabular}{|c|c|c|c|c|c|c|}
\hline & $\begin{array}{l}(1) \\
\text { OLS }\end{array}$ & $\begin{array}{c}(2) \\
\text { OLS }\end{array}$ & $\begin{array}{c}(3) \\
\text { OLS }\end{array}$ & $\begin{array}{c}(4) \\
\text { OLS }\end{array}$ & $\begin{array}{c}(5) \\
\text { probit }\end{array}$ & $\begin{array}{c}(6) \\
\text { probit }\end{array}$ \\
\hline thinking & -0.015 & -0.037 & -0.027 & -0.018 & -0.061 & -0.079 \\
\hline treatment & $(0.039)$ & $(0.044)$ & $(0.041)$ & $(0.039)$ & $(0.158)$ & $(0.163)$ \\
\hline higher price & $\begin{array}{c}-0.541 \\
(0.041)\end{array}$ & $\begin{array}{l}-0.555 \\
(0.045)\end{array}$ & $\begin{array}{l}-0.564 \\
(0.041)\end{array}$ & $\begin{array}{c}-0.545 \\
(0.040)\end{array}$ & $\begin{array}{c}-1.522 \\
(0.150)\end{array}$ & $\begin{array}{c}-1.633 \\
(0.158)\end{array}$ \\
\hline interaction & $\begin{array}{c}0.107 \\
(0.050)\end{array}$ & $\begin{array}{c}0.122 \\
(0.056)\end{array}$ & $\begin{array}{c}0.127 \\
(0.053)\end{array}$ & $\begin{array}{c}0.110 \\
(0.051)\end{array}$ & $\begin{array}{c}0.311 \\
(0.180)\end{array}$ & $\begin{array}{c}0.347 \\
(0.189)\end{array}$ \\
\hline $\begin{array}{l}\text { village } \\
\text { fixed effects } \\
\text { surveyor } \\
\text { fixed effects }\end{array}$ & & & & $\begin{array}{c}F_{7,12}=8629 \\
p=0.00 \\
F_{4,12}=2.08 \\
p=0.15\end{array}$ & & $\begin{array}{c}\chi^{2}=3464 \\
p=0.00 \\
\chi^{2}=9.82 \\
p=0.04\end{array}$ \\
\hline constant & $\begin{array}{c}0.839 \\
(0.040)\end{array}$ & $\begin{array}{c}0.848 \\
(0.044)\end{array}$ & $\begin{array}{c}0.872 \\
(0.038)\end{array}$ & $\begin{array}{c}0.766 \\
(0.064)\end{array}$ & $\begin{array}{c}0.992 \\
(0.164)\end{array}$ & $\begin{array}{c}0.785 \\
(0.219)\end{array}$ \\
\hline$n$ & 647 & 576 & 625 & 647 & 647 & 647 \\
\hline clusters & 13 & 13 & 13 & 13 & 13 & 13 \\
\hline$R^{2}$ & 0.25 & 0.26 & 0.27 & 0.29 & 0.19 & 0.23 \\
\hline
\end{tabular}

Table 7: Alternative inference strategies for $\beta_{3}$

\begin{tabular}{lccccc}
\hline \hline & interaction & $\begin{array}{c}\text { standard } \\
\text { error }\end{array}$ & $\begin{array}{c}\text { test } \\
\text { statistic }\end{array}$ & $\begin{array}{c}\text { one-sided } \\
p\end{array}$ & $\begin{array}{c}\text { two-sided } \\
p\end{array}$ \\
\hline OLS, clustered standard errors & & & & & \\
$\quad$ asymptotic normality & 0.107 & 0.050 & $z=2.12$ & 0.017 & 0.034 \\
inflate s.e. by $\sqrt{\frac{C}{C-1}}$ & & 0.053 & $z=2.04$ & 0.021 & 0.041 \\
$t, C-1$ degrees of freedom & & 0.050 & $t_{12}=2.12$ & 0.028 & 0.055 \\
$\quad t, C-K$ degrees of freedom & 0.050 & $t_{10}=2.12$ & 0.030 & 0.060 \\
wild cluster bootstrap $t$ & & $w_{b}=2.12$ & 0.032 & 0.059 \\
$\quad(10,000$ repetitions) & & & & \\
& & & & \\
average $\frac{1}{C} \sum_{c} \hat{\beta}_{3}^{c}$, OLS by cluster & \multirow{2}{*}{0.104} & 0.047 & $t_{12}=2.23$ & 0.023 & 0.046 \\
$t$ test, $n=13$ & & $z=2.20$ & & 0.028 \\
$\quad$ signed rank test, $n=13$ & & & & & \\
\hline
\end{tabular}




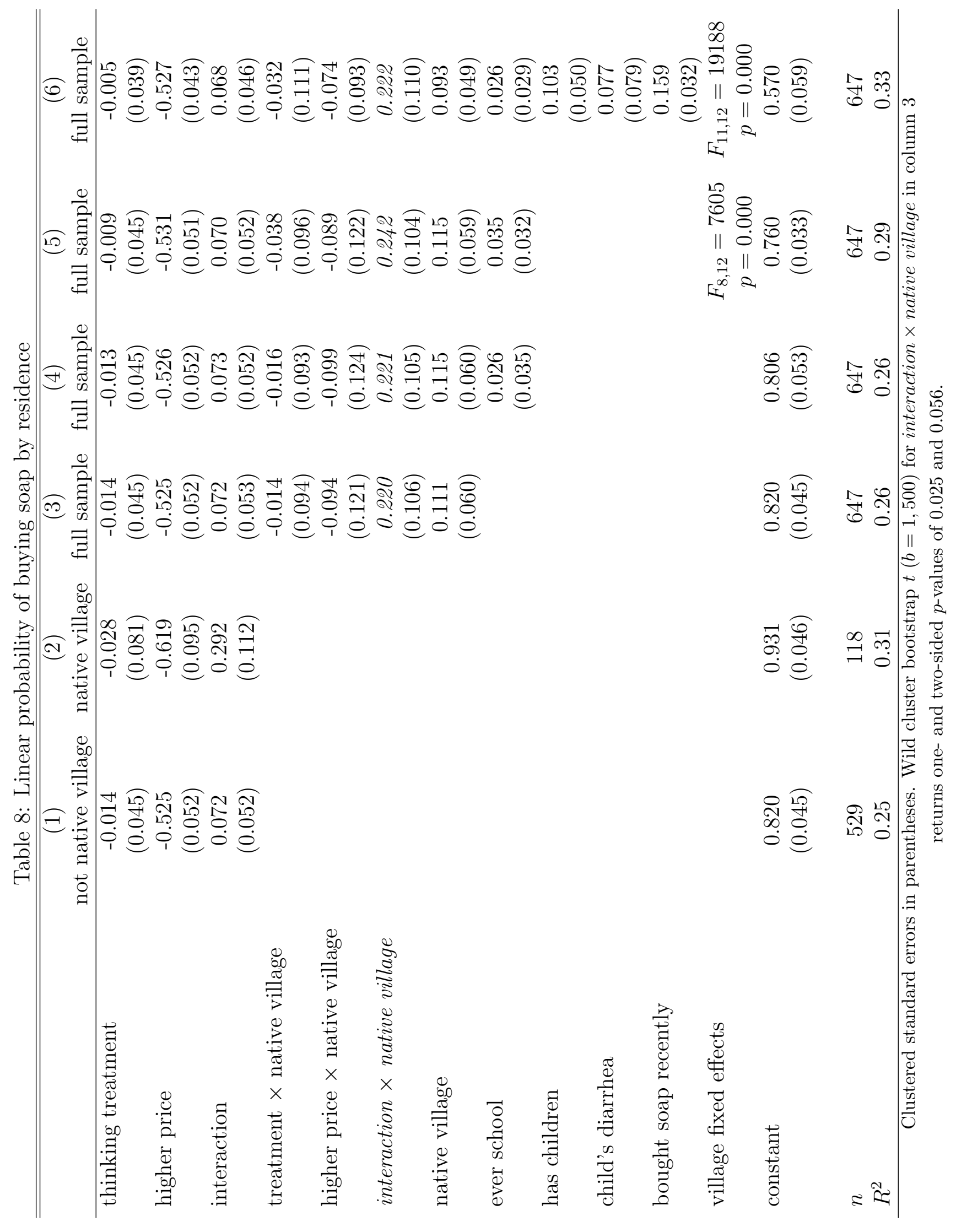


Table 9: Deliberation costs and screening: linear probability of need among buyers

\begin{tabular}{lccccccc}
\hline \hline & \multicolumn{3}{c}{ children's diarrhea } & & \multicolumn{3}{c}{ children in the household } \\
\cline { 2 - 4 } \cline { 6 - 8 } & $(1)$ & $(2)$ & $(3)$ & & $(4)$ & $(5)$ & $(6)$ \\
& control & treatment & full sample & & control & treatment & full sample \\
\hline higher price & -0.028 & 0.098 & -0.028 & & 0.013 & 0.089 & 0.013 \\
& $(0.051)$ & $(0.040)$ & $(0.051)$ & & $(0.058)$ & $(0.046)$ & $(0.058)$ \\
thinking & & & -0.037 & & & -0.037 \\
treatment & & & $(0.026)$ & & & $(0.043)$ \\
interaction & & & 0.126 & & & 0.076 \\
& & & $(0.058)$ & & & $(0.091)$ \\
constant & 0.132 & 0.096 & 0.132 & & 0.882 & 0.846 & 0.882 \\
& $(0.025)$ & $(0.033)$ & $(0.025)$ & & $(0.023)$ & $(0.028)$ & $(0.023)$ \\
$n$ & & & & & & \\
$n$ (soap buyers) & 184 & 198 & 382 & & 184 & 198 & 382 \\
clusters & 13 & 13 & 13 & & 13 & 13 & 13 \\
$R^{2}$ & 0.00 & 0.02 & 0.01 & & 0.00 & 0.02 & 0.01 \\
\hline
\end{tabular}

Clustered standard errors in parentheses.

Table 10: Theories, predictions, and results

\begin{tabular}{lcccccc}
\hline \hline & \multicolumn{3}{c}{ deliberation } & & \\
\cline { 2 - 5 } predictions by theory & $\beta_{1}$ & $\beta_{2}$ & $\beta_{3}$ & & wealth & screening \\
\hline bounded rationality & $0 /-$ & - & + & $\beta_{3}$ larger for poor & when $c=0$ \\
$\quad$ as deliberation costs & & & & & \\
standard preferences & 0 & - & 0 & no prediction & ordinarily \\
present-biased preferences & 0 & - & 0 & no prediction & no prediction \\
affect about low prices & - & - & $-\beta_{1}$ & no prediction & no prediction \\
experimenter demand & + & - & $0 /-$ & no prediction & no prediction \\
\hline results & $0 /-$ & - & + & $\beta_{3}$ larger for poor & when $c=0$ \\
\hline
\end{tabular}

Table 11: Village endogamy: sample means and standard errors

\begin{tabular}{cccccccc}
\hline \hline & $\begin{array}{c}\text { from } \\
\text { village }\end{array}$ & $\begin{array}{c}\text { village } \\
\text { endogamy }\end{array}$ & $\begin{array}{c}\text { annual } \\
\text { income (Rs.) }\end{array}$ & $\begin{array}{c}\text { asset } \\
\text { count }\end{array}$ & $\begin{array}{c}\text { owns } \\
\text { land }\end{array}$ & $\begin{array}{c}\text { ever } \\
\text { school }\end{array}$ & $\begin{array}{c}\text { Uttar } \\
\text { Pradesh }\end{array}$ \\
\hline & 0.09 & 0.13 & 17,666 & 2.35 & 0.69 & 0.26 & 0.57 \\
& $(0.01)$ & $(0.01)$ & $(589)$ & $(0.06)$ & $(0.01)$ & $(0.01)$ & $(0.01)$ \\
\hline$n$ & 1857 & 1480 & 1878 & 1891 & 1878 & 1891 & 1891 \\
\hline \multicolumn{7}{c}{ Data provided by Desai and Rao (1995). }
\end{tabular}




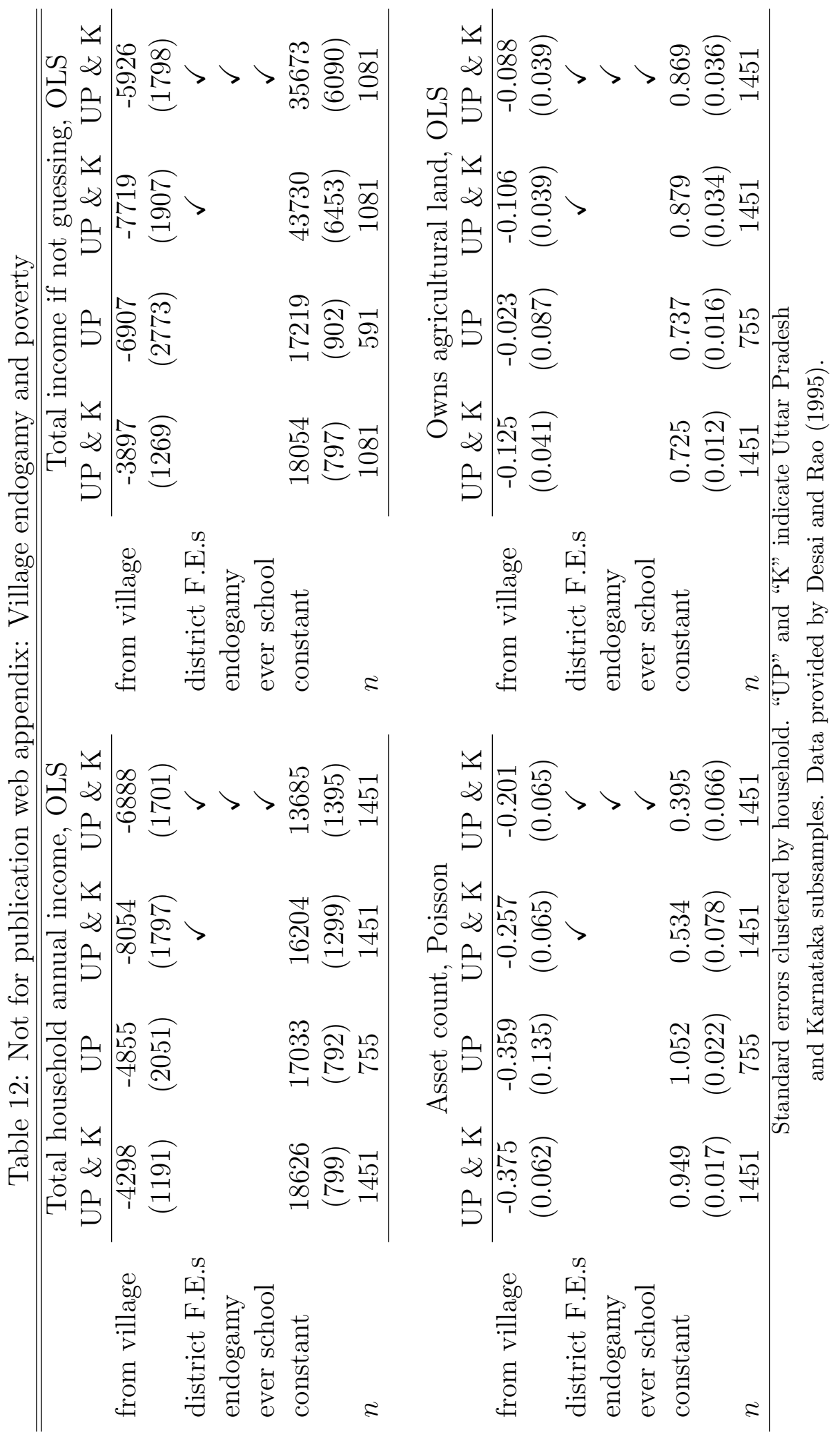

